\title{
A COMPARISON OF SEASONAL AND INTERANNUAL VARIABILITY OF SOIL DUST AEROSOLS OVER THE ATLANTIC OCEAN AS INFERRED BY THE TOMS AI AND AVHRR AOT RETRIEVALS
}

\author{
R. V. Cakmur \\ Department of Applied Physics, Columbia University, New York, New York. \\ R. L. Miller \\ Department of Applied Physics, Columbia University, New York, New York. \\ NASA Goddard Institute for Space Studies, New York, New York.
}

Ina Tegen

Max-Planck Institute for Biogeochemistry, Jena, Germany.

\begin{abstract}
The seasonal cycle and interannual variability of two estimates of soil (or 'mineral') dust aerosols are compared: Advanced Very High Resolution Radiometer (AVHRR) aerosol optical thickness (AOT) and Total Ozone Mapping Spectrometer (TOMS) aerosol index (AI). Both data sets, comprising more than a decade of global, daily images, are commonly used to evaluate aerosol transport models. The present comparison is based upon monthly averages, constructed from daily images of each data set for the period between 1984 and 1990, a period that excludes contamination from volcanic eruptions. The comparison focuses upon the Northern Hemisphere subtropical Atlantic Ocean, where soil dust aerosols make the largest contribution to the aerosol load, and are assumed to dominate the variability of each data set. While each retrieval is sensitive to a different aerosol radiative property - absorption for the TOMS AI versus reflectance for the AVHRR AOT - the seasonal cycles of dust loading implied by each retrieval are consistent, if seasonal variations in the height of the aerosol layer are taken into account when interpreting the TOMS AI. On interannual time scales, the correlation is low at most locations. It is suggested that the poor interannual correlation is at least partiy a consequence of data availability. When the monthly averages are constructed using only days common to both data sets, the correlation is substantially increased: this consistency suggests that both TOMS and AVHRR accurately measure the aerosol load in any given scene. However, the two retrievals have only a few days in common per month so that these restricted monthly averages have a large uncertainty. Calculations suggest that at least 7 to $\mathbf{1 0}$ daily images are needed to estimate reliably the average dust load during any particular month, a threshold that is rarely satisfied by the AVHRR AOT due to the presence of clouds in the domain. By rebinning each data set onto a coarser grid, the availability of the AVHRR AOT is increased during any particular month, along with its interannual correlation with the TOMS AI. The latter easily exceeds the sampling threshold due to its greater ability to infer the aerosol load in the presence of clouds. Whether the TOMS AI should be regarded as a more reliable indicator of interannual variability depends upon the extent of contamination by sub-pixel clouds.
\end{abstract}

\section{Introduction}

Despite the increase in globally averaged surface temperature over the past few decades, some regions of the world have actually cooled [Houghton et al., 1996; Hansen et al., 1999]. Regional variations in the observed warming have drawn attention to aerosols, whose distributions are highly variable in space and time [Charlson et al., 1992; Duce, 1995; Tegen et al., 1996]. Acrosols per- turb the Earth's climate in two ways: first, by absorbing and scattering solar and terrestrial radiation (the 'direct' effect), and by acting as condensation nuclei for cloud droplets, thus changing cloud optical properties and lifetimes (the 'indirect' effect). By mass, the most common aerosols are soil particles lofted from dry land surfaces by the wind [Andreae, 1995; Tegen et al., 1997]. Soil dust (also known as mineral dust) is one of the largest contributors to aerosol radiative forcing, and may have 
increased in time as a consequence of human disturbance of soil surfaces through agriculture, deforestation, and overgrazing [Tegen et al., 1996]. In order to quantify the natural and anthropogenic components of radiative forcing by soil dust aerosols and their effect upon climate, one needs continuous and global measurements of both their horizontal and vertical distribution.

Original estimates of aerosol distribution and transport were derived from ground-based measurements. For soil dust aerosols, the observational record at certain locations extends back several decades to the 1960's [Carlson and Prospero, 1972; Prospero et al., 1981; Prospero and Nees, 1986; Duce, 1995]. These observations allow inferences about particular source regions, but they are not sufficient to map the global distribution of dust aerosols, which has large regional variability. In the past two decades, satellite measurements have provided detailed inferences of the horizontal distribution of dust aerosols over specific regions as well as over the entire globe [Moulin et al., 1997b; Husar et al., 1997; Herman et al., 1997; King et al., 1999]. Satellite estimates of the seasonal cycle and interannual variability of dust aerosols are a useful test of models that predict the aerosol distribution (e.g.,[Tegen and Fung, 1994, 1995; Tegen and Miller, 1998]). In particular, the observed horizontal distribution of soil dust aerosols can be used to evaluate atmospheric general circulation model (AGCM) parameterizations of dust uplift, transport, and deposition. AGCMs are essential to calculate the climate response to aerosol forcing [Miller and Tegen, 1998], including the anthropogenic component, and this estimate will depend upon the validity of the dust parameterization.

There are many satellite estimates of the aerosol load [King et al., 1999]. However, because of their global coverage and multi-decadal span, two retrievals are particularly attractive to aerosol modelers in their effort to evaluate the distribution of soil dust calculated by their models: Advanced Very High Resolution Radiometer (AVHRR) Aerosol Optical Thickness (AOT) and Total Ozone Mapping Spectrometer (TOMS) Aerosol Index (AI). This paper compares the seasonal cycle and interannual variability of soil dust aerosols over the Northern Hemisphere (NH) subtropical Atlantic as inferred from these two retrievals. While each dataset contains acknowledged uncertainties [Husar et al., 1997; Herman et al., 1997; Torres et al., 1998], consistent features on various time scales could be used to evaluate dust parameterizations in the $\mathrm{AGCM}$.

Comparison of the two retrievals requires some care. Both TOMS and AVHRR are sensitive to the AOT within the column, but the TOMS AI depends additionally upon the height of the aerosol layer, which has a pronounced seasonal cycle [Carlson and Prospero, 1972; Chiapello et al., 1995]. In section 2, we describe each retrieval, and the conditions under which an AOT and AI can be compared. In section 3 , we show that each retrieval implies a consistent seasonal cycle of the dust load, if observed seasonal variations in the height of aerosol transport are accounted for when interpreting the TOMS AI. In contrast, the agreement between interannual variations in the two retrievals - measured by correlating monthly averages of each retrieval after removing the seasonal cycle - is much smaller. In section 4 , we show that the interannual correlation is substantially increased when the monthly averages are formed using only days for which both retrievals are available. This high correlation suggests that TOMS and AVHRR form similar estimates of the dust load within any particular scene. We suggest two reasons for the poor interannual correlation of the monthly averages, when constructed using all the days available in each data set. First, the presence of clouds may preclude a sufficient number of AVHRR retrievals in any particular month to allow the accurate estimation of the monthly average along with month to month variability. Second, undetected clouds at the sub-pixel scale may introduce uncertainty into the TOMS AI. Our conclusions are presented in Section 5.

\section{Datasets}

TOMS detects the presence of absorbing aerosols such as soil dust, smoke, and soot, based upon departures of backward scattered UV radiation from pure Rayleigh scattering. An aerosol index (AI) is constructed using the spectral contrast between the 340 and $380 \mathrm{~nm}$ channels [Herman et al., 1997; Torres et al., 1998]. The AI depends upon the aerosol optical thickness (AOT), height of the aerosol layer, optical properties of the aerosol particles, and instrument viewing angle. [Hsu et al., 1999] use measurements from ground-based sun photometers to show that daily variations of the AOT and AI have an approximate linear relationship; weak spatial and seasonal variability of the regression coefficient relating the AOT and $A I$ is attributed to variations in the height of the aerosol layer. TOMS detects aerosols not only over the water but also over land, because the UV reflectivity of the Earth's surface is very small except for regions covered by snow and ice [Herman et al., 1997]. However, because a low altitude absorbing aerosol layer creates only a small perturbation upon the upwelling $\mathrm{UV}$, the AI cannot distinguish soil dust within roughly a kilometer of the surface from more weakly absorbing aerosol types or clouds. [Herman et al., 1997; Torres et al., 1998; Hsu et al., 1999].

In contrast, AVHRR measures reflectance at the $630 \mathrm{~nm}$ wavelength to derive an AOT corresponding to all aerosol types - including weakly absorbing aerosols like industrial sulfates -- throughout the entire thickness of the atmospheric column. However, AVHRR is limited to retrieval over the ocean because of the difficulty presented by the nonuniform reflectivity of the Earth's land surface at $630 \mathrm{~nm}$. [Husar et al., 1997]. AVHRR derives an aerosol optical thickness assuming Mie scattering by spherical particles. In fact, dust aerosols are non-spherical, and this assumption may introduce errors in retrieval [Mishchenko et al., 1995]. Furthermore, 
the AOT retrieval assumes a mean particle radius of $0.1 \mu \mathrm{m}$, a value that is appropriate for sulfate aerosols but smaller than typical dust particle sizes [Tegen and Lacis, 1996; Moulin et al., 1997c]. The Mie scatterers are assumed to be perfect reflectors, with a single scattering albedo of unity; again, this is a better approximation for sulfate aerosols than soil dust [Hansen et al., 1998]. Lastly, the ocean albedo is assumed to be independent of the overpass time of day. To measure the uncertainty introduced by these assumptions, the original AVHRR AOT retrieval was compared to sun photometer measurements [Ignatov et al., 1995]. As a result, a second generation retrieval of AOT was derived, which is used in this study.

In the next section, we correlate dust variability as inferred by the TOMS AI and AVHRR AOT. This comparison is complicated by two factors. First, the retrievals do not detect soil dust per se, but rather aerosol absorption (TOMS) and reflection (AVHRR), and thus potentially detect additional aerosol types. We choose for our domain of comparison the NH subtropical Atlantic Ocean, because the aerosol load in this region is dominated by soil dust originating from North Africa (e.g., [Li et al., 1996; Tegen et al., 1997; Chiapello et al., 1999]). In this region, we assume that both retrievals predominately record variations of soil dust, excluding North American industrial sulfates potentially present in AVHRR, and carbonaceous aerosols from southern African biomass burning in TOMS.

The second complication results from the slightly different physical quantities represented by each retrieval: as noted above, the daily AI retrievals depend upon aerosol height, single scatter albedo, and instrument viewing angle, in addition to AOT. On daily and seasonal time scales, variations of the aerosol layer height are large enough that the AI and AOT are not directly comparable. To minimize the effect of synoptic and mesoscale variations in the height of aerosol transport and its effect upon the AI, we compare monthly averages of the two data sets, rather than the original daily values. (The use of monthly averages also minimizes the importance of the instrument viewing angle, which otherwise imposes cyclic variations upon the AI with the 6 day overpass frequency of the satellite.) Monthly averages of the AI remain sensitive to seasonal and interannual variations in the height of the aerosol layer. During the $\mathrm{NH}$ summer, soil dust originating from Africa traverses the Atlantic. Ocean in a layer centered a few kilometers above the surface [Carlson and Prospero, 1972]. In contrast, wintertime transport across the Atlantic occurs adjacent to the surface [Chiapello et al., 1995]. To compare the seasonal cycle of dust loading inferred by TOMS and AVHRR, we will attempt to account for the variation in layer height using the theoretical calculations of AI by [Torres et al., 1998]. We are particularly interested in whether the TOMS AI corroborates the amplitude of the AVHRR seasonal cycle, since certain dust models underestimate this cycle downwind of the
Sahara, compared to the AVHRR retrieval (e.g. [Tegen et al., 1997]).

On interannual time scales, we assume that the AI and AOT are directly comparable. That is, after removal of the seasonal cycle, variations in the height of the aerosol layer are assumed to be of secondary importance to the AI. An identical assumption is made by [ $\mathrm{Hsu}$ et al., 1999] who interpreted interannual changes in the AI as a proxy for changes in the AOT.

The AVHRR retrievals are available on a uniform $1^{\circ}$ longitude by $1^{\circ}$ latitude grid while TOMS is on a $1.25^{\circ}$ by $1^{\circ}$ grid. Both datasets are gridded at the same latitudes; in order to match the two grids with respect to longitude, each TOMS point is matched with the closest AVHRR point. Both data sets are available on a daily basis, but on any given day, data is missing at certain locations. In the case of TOMS, sea-glint at the nadir point prevents retrieval over ocean locations roughly every 6 days, which corresponds to the overpass frequency. For AVHRR, this frequency is around 9 days, and retrievals at any location are available roughly half of the time, when the location is on the side of the satellite away from the sun.

In practice, the presence of clouds further limits the availability of each retrieval. Clouds exhibit a small departure from Rayleigh scattering at the AI wavelengths [Herman et al., 1997]. Thus, a small value of the TOMS AI may represent a scene where the aerosol layer is almost entirely obscured by clouds - and cannot be retrieved accurately - or else a clear scene with no aerosols present. To distinguish these two cases, we choose a reflectivity threshold to be compared to the TOMS $380 \mathrm{~nm}$ reflectivity. If the reflectivity exceeds the threshold, say 15 percent, then we assume that the AI is adulterated by the presence of clouds, and discard the retrieval for that particular day. We also discard values of the AI less than zero, since this is generally the signature of either clouds or a layer of weakly absorbing aerosols like sulfates. We find that the correlation between the TOMS AI and AVHRR AOT is insensitive to whether a reflectivity threshold of 15 or 25 percent is chosen. The results presented in this article are based upon the more stringent 15 percent threshold unless otherwise noted. Over the NH subtropical Atlantic, where the dust concentration is highest (e.g., [Moulin et al., 1997b; Husar et al., 1997; Herman et al., 1997], the presence of clouds and weakly absorbing aerosols cause slightly more than half of the daily TOMS AI retrievals to be discarded during any particular month; monthly averages are constructed on average from 10 to 15 daily retrievals (Fig. 1a). For comparison, a reflectivity threshold of 25 percent makes available roughly 5 extra days per month. Fig. 1a represents the availability averaged over the entire period of comparison; in the $\mathrm{NH}$ subtropics, availability varies from month to month with a standard deviation of around 4 days.

The presence of clouds leads to a greater reduction in the availability of the AVHRR daily retrievals. In 
the AVHRR AOT retrieval algorithm, clouds are distinguished from aerosols by their spectral signature, using a test that is effective for values of the AOT less than 2 [Husar et al., 1997] - in fact, we found few daily values of AOT within our domain that exceeded 1.2, and none above 1.5. Over the tropical Atlantic, daily retrievals are typically available fewer than 10 days per month, and less near the Intertropical Convergence Zone (ITCZ), as shown in Fig. 1b. The standard deviation of month to month variations in availability ranges from 2 to 3 days. We will consider the effect of data availability upon the correlation of the two retrievals in Section 4.

Sub-pixel clouds that remain undetected introduce uncertainty into each retrieval, causing the aerosol load to be underestimated by the TOMS AI and overestimated by the AVHRR AOT [Torres et al., 1998]. A larger uncertainty is introduced into the former as a result of its larger instrument footprint. This effect, which we are unable to quantify, would reduce the correlation between the two retrievals.

From the nearly two decades of retrievals available within each data set, we examine the seven-year period from 1984 to 1990 , which excludes any contamination from the volcanic eruptions of El Chichon and Pinatubo. At each location, monthly averages are formed from a minimum of 3 daily retrievals within each month: this threshold is easily exceeded by TOMS, but somewhat reduces the number of AVHRR monthly averages that can be formed. At grid points lacking 3 daily retrievals in a particular month, the monthly average is constructed using linear interpolation between the monthly averages of the preceding and following months. Interpolation is applied only at grid points having at least 63 months with 3 daily retrievals or more (out of a maximum possible 84 months); otherwise, the grid point is excluded from the analysis. Interpolation allows the correlation to include months when only one retrieval contains three or more daily images. (Nonetheless, our results are qualitatively unchanged when these months are omitted.) The 63 month threshold is chosen to exclude from our analysis locations that are consistently devoid of data. We also correlate the retrievals limiting ourselves to the summer months (June to September, with 28 potential months over 7 years); the threshold is 21 months. Finally, to compare the interannual variations of each retrieval, monthly anomalies are constructed by forming a seven-year average of each of the 12 calendar months at every grid point and subtracting this seasonal cycle from the monthly averages.

\section{Comparison of Seasonal and Interannual Variations}

The spatial distribution of the TOMS AI and AVHRR AOT retrievals are shown in Fig. 2. The figure illustrates the various aerosol types contributing to the annual and summertime mean of each retrieval. Both show an optically thick aerosol plune extending across the Atlantic from North Africa, which ground-based measurements identify as dust originating from the fringes of the Sahara during NH summer and additionally from the Sahel during winter [Carlson and Prospero, 1972; Chiapello et al., 1995; Li et al., 1996; Chiapello et al., 1999]. The plume extending westward off the coast of Southern Africa is attributed to carbonaceous aerosols formed by biomass burning during the dry season (e.g., [Hsu et al., 1999]). The AVHRR retrieval shows an additional plume extending eastward from North America into the North Atlantic, which is interpreted as sulfate aerosols created by industrial pollution [Husar et al., 1997].

Based upon in situ observations (e.g. [Carlson and Prospero, 1972; Chiapello et al., 1999], we define a 'dust region,' extending from $40.5^{\circ} \mathrm{W}$ to $18.125^{\circ} \mathrm{W}$ longitude (near the African coast), and from $5.5^{\circ} \mathrm{N}$ to $25.5^{\circ} \mathrm{N}$ latitude, where soil dust is the dominant aerosol type. In this region, we expect that both the TOMS AI and the AVHRR AOT will record mainly the presence of soil dust, and that any potential agreement between the two retrievals will not be degraded by other aerosol types for which each retrieval has a different sensitivity. Figs. $3 a$ and $b$ show the seasonal cycle within the dust region. Longitudinal variations are small (not shown), except for a gradual decrease in amplitude to the west; in the figure, we average each retrieval longitudinally across the dust region. Near the equator, the aerosol load peaks during $\mathrm{NH}$ winter; as summer approaches and the ITCZ moves northward, the trade winds that transport the dust shift poleward as well, so that at northern latitudes, each retrieval peaks during the summer [Swap et al., 1996]. A similar northward shift in dust transport during NH summer is indicated by Meteosat images [Moulin et al., 1997a]. The shift is accompanied by seasonal changes in the land source region. Saharan dust is transported over the Cape Verde Islands $\left(24^{\circ} \mathrm{W}\right.$, $16^{\circ} \mathrm{N}$ ) throughout the year, while the occurrence of easterly Trade winds at the surface during the winter brings dust additionally from source regions in the Sahel [Chiapello et al., 1995]. The seasonal cycle is more pronounced in the TOMS AI retrieval, as indicated by Fig. 4, which shows the ratio of the AI and AOT as a function of calendar month, averaged along $15.5^{\circ} \mathrm{N}$ between the longitudes of Dakar and the Cape Verde Islands. Note also that the summertime maximum of the $\mathrm{AI}$ at northern latitudes is roughly twice the winter maximum that occurs to the south (Fig. 3a). In contrast, the maximum value of the AVHRR AOT shows little variation with latitude.

These contrasts can be attributed to seasonal changes in the height of the aerosol layer. Aerosol transport off North Africa during the NH summer occurs in an elevated layer centered near $700 \mathrm{mb}$ [Carlson and Prospero, 1972], whereas wintertime transport is centered closer to the surface, near $900 \mathrm{mb}$ [Chiapello et al., 1995]. Conversion of the TOMS AI into an equivalent AOT at the $630 \mathrm{~nm}$ wavelength retrieved by AVHRR involves two steps. First, Fig. 1 of [Hsu et al., 1999], which 
is based upon calculations by [Torres et al., 1998], is used together with the aerosol layer height to convert the AI into a $380 \mathrm{~nm}$ AOT. Second, this AOT is converted into a $630 \mathrm{~nm}$ value, using a theoretical model of AOT dependence upon wavelength and the Angstrom exponent parameter derived from sun photometer measurements. Based upon such measurements in regions where the aerosol load is dominated by dust, [Hsu et al., 1999] derive an Angstrom exponent that indicates the $630 \mathrm{~nm}$ AOT is approximately the same as the $380 \mathrm{~nm}$ value. (More precisely, the latter is roughly $5 \%$ larger.) Thus, the most important factor in relating the AI to an AVHRR AOT is the aerosol height. Based upon Fig. 1 of [Hsu et al., 1999], the effect of raising the aerosol layer from its wintertime level near $900 \mathrm{mb}$ to its summer elevation of $700 \mathrm{mb}$ would by itself increase the AI by a factor of just over two. This is consistent with the seasonal contrast of the ratio of the TOMS AI and AVHRR AOT shown in Fig. 4. This is also roughly the ratio of the summer and winter maxima of the AI (Fig. 3a). Thus, both retrievals suggest that the amount of dust transported off Africa remains constant throughout the year, even as latitude of transport varies. Clearly, our attempt to infer seasonal variations in AOT from the TOMS AI by accounting for seasonal variations in the height of aerosol layer is limited by the uncertainty in this height; a more precise comparison would require detailed information on the vertical distribution of the aerosol transport. Nonetheless, the present comparison suggests that the seasonal cycles of AOT inferred from the two retrievals are roughly consistent with each other; differences in the two retrievals themselves can be attributed to seasonal variations in the height of the aerosol layer.

Interannual variations in the two data sets, calculated by removing the seasonal cycle from the monthly averages, have a spatial distribution resembling the time average, as indicated by the standard deviation of the interannual variability, shown in Fig. 5 . The standard deviation measures the typical amplitude of each retrieval's monthly anomalies; our correlation of these anomalies from the two data sets is meaningful to the extent that this amplitude (the 'signal') is larger than the uncertainty (the 'noise') of each retrieval. The uncertainty of gridded daily images of the TOMS AI is estimated to be 0.2 [Hsu et al., 1999], while that of the AVHRR AOT is estimated at less than 0.04 [Stowe et al., 1997]. The uncertainty of the monthly averages and anomalies should be further reduced from the daily value by roughly the square-root of the number of independent observations available each month. Independent measurements of the dust aerosol amount are separated by roughly three days, according to Fig. 6a, which shows the lag autocorrelation of the TOMS AI falling to zero over this duration. We estimate the number of independent daily images available in each month by counting the number of successive images spaced three or more days apart. (For example, daily images available on the first, fourth, and seventh day of the month would be counted as three independent measurements, whereas images available on the first, second, and fifth would count only as two.) Figs. $6 \mathrm{~b}$ and $\mathrm{c}$ show that within the dust region, roughly 4 AVHRR AOT images and 6 TOMS AI images are independent each month. This is a conservative estimate of availability since images from adjacent days are not entirely redundant. In any case, the uncertainty of the monthly averages and anomalies can be estimated to be less than half of the uncertainty of daily images cited above. Over the NH subtropical Atlantic, this is exceeded by the standard deviation of each retrieval (Fig. 5). Thus, month to month variations in the two data sets predominately record variations in aerosol absorption and reflectance rather than measurement uncertainty, a necessary condition for our comparison of interannual variability. This dominance is especially large near the African coast, close to the source region, where the standard deviation is largest.

Fig. 7a shows the month to month variations of each retrieval averaged over the dust region for the period of comparison. The two time series exhibit reasonable resemblance, as reflected by the correlation coefficient of 0.66 . This agreement is partly due to agreement of the seasonal cycle in each data set (Fig. $7 \mathrm{~b}$ ); both retrievals identify the same month corresponding to maximum transport as a function of latitude (Fig. 3). Year to year variations can be compared by removing the seasonal cycle (Fig. 7b). As noted in the previous section, we assume that interannual variations in the height of the aerosol layer are of secondary importance to the AI, so that on interannual time scales, it can be compared directly to the AVHRR AOT. In the absence of the seasonal cycle, the correlation of the two retrievals is reduced to 0.55 (Fig. $7 \mathrm{c}$ ). The variance shared by the two data sets, equal to the square of the correlation coefficient, is roughly 30 percent.

When the two retrievals are compared at individual grid points, the removal of the seasonal cycle leads to a greater reduction in the correlation coefficient. Fig. 8a shows the spatial distribution of the correlation coefficient prior to the removal of the seasonal cycle; locations without sufficient data to form at least 63 monthly averages are denoted by dots. The predominance of dust scattering over that by other aerosol types and the predominance of the month to month variations of each retrieval over measurement uncertainty, two assumptions upon which the validity of this comparison depends, are best satisfied within our dust region defined above. Nonetheless, the figure displays the correlation over a broader area than the dust region in order to encompass the substantial dust concentrations that are observed to the north [Moulin et al., 1997a] and downwind toward Barbados [ $L i$ et al., 1996] during certain months of the year. According to Fig. 8a, correlations that are high given the inclusion of the seasonal cycle, are generally reduced when the seasonal cycle is removed (Fig. 8b). Despite agreement on the seasonal cycle of dust loading, the TOMS AI and AVHRR AOT are not well correlated on interannual time scales. 
The uncertainty in the TOMS AI retrieval of soil dust is potentially largest during the $\mathrm{NH}$ winter, when the aerosol layer is closest to the surface, resulting in a low value of the $A I$ that could be adulterated by the presence of more weakly absorbing aerosols or clouds. In contrast, summertime transport of dust across the Atlantic occurs well above the surface, where its AI signature is much stronger compared to that of other aerosol types. Furthermore, POLDER ${ }^{1}$ estimates of Angstrom coefficients show evidence of biomass burning and soot aerosols in the southeast corner of the dust region during November and December (at least for the year 1996; [Chiapello et al., 2000]). To remove these effects upon our comparison, which introduce uncertainty into the soil dust estimates, we repeat the correlation restricting ourselves to just the summer months (June to September), distinguished by a darker line in Fig. 7. The correlation in the absence of the seasonal cycle, equal to 0.07 , is evidently not improved compared to the value computed using all months, which is also the case at individual grid points, as shown in Fig. 8d. The disagreement between the monthly anomalies of the TOMS AI and AVHRR AOT is not due to the lower level of aerosol transport during NH winter, nor the presence of soot aerosols during this season. We also restricted the correlation to the period between Jan 1985 and Dec 1987, when the AVHRR retrievals were provided almost exclusively by the NOAA-9 satellite; while this minimized the effects of inter-satellite calibration, the correlations were not increased (results not shown).

\section{Estimation of Retrieval Monthly Averages}

The TOMS AI and AVHRR AOT provide consistent estimates of the seasonal cycle of the dust aerosol load over the $\mathrm{NH}$ subtropical Atlantic, if seasonal variations in the height of transport are taken into account. However, the monthly anomalies share far less variance. Here, we suggest that the weak interannual correlation is at least partly the result of clouds that limit the availability of daily images comprising the monthly averages of each retrieval (c.f. Fig. 1). Below, we show that the two retrievals are highly correlated when the monthly averages and anomalies are constructed using only days when both retrievals are available. The large shared variance suggests that both retrievals consistently and accurately measure the dust load of any particular scene. However, we also show that only the TOMS AI has a sufficient number of daily retrievals to estimate precisely the average for any particular month; the low interannual correlation of monthly anomalies comprised of all of the data (Fig. $8 \mathrm{~b}$ ) reflects in part the large uncertainty in the AVHRR AOT monthly anomalies.

Fig. 9 shows the correlation of the two data sets, when

${ }^{1}$ POI.DER: polarization and directionality of the Earth's reflectances the monthly averages are restricted to days when both the TOMS AI and AVHRR AOT retrievals are available. Clouds are absent from these scenes, which otherwise prevent retrieval by AVHRR and TOMS, the latter to a lesser extent. The monthly anomalies are correlated at a substantially higher level (Fig. 9b), compared to the anomalies formed using all the available days (Fig. 8b). The correlation is near 0.7 within the dust region, indicating that the two retrievals share as much as half their variance. The correlation and shared variance are even higher when restricted to summer months (Fig. 9d). While the two retrievals are highly correlated when their monthly averages are constructed from identical scenes, these monthly averages have a potentially large uncertainty, being constructed from only a small number of daily retrievals. Fig. 10 shows the number of common days available for each of the 84 months, averaged over the grid points within the dust region. Reflecting the relative paucity of AVHRR daily retrievals, this value is around 3 days with a standard deviation at individual grid points of just under 2 .

Next, we consider how many daily retrievals are needed to estimate precisely the monthly anomalies, and whether either retrieval satisfies this threshold. To estimate the minimum number of daily retrievals needed to form an accurate monthly average, we correlate two versions of the TOMS AI monthly averages with the seasonal cycle removed from each. In one version, the full number of available days is used to form the monthly averages. In the second (or 'degraded') version, averages are formed after removing observations at random. That is, the monthly averages in the degraded version are formed with less than the full amount of available retrievals. The question we ask is how many retrievals can be discarded before the two versions of the data set are no longer well correlated. Because the uncertainty in a degraded monthly average increases as days are discarded - along with the potential error - this calculation provides an estimate of the minimum number of daily retrievals required to estimate accurately the average of any particular month.

Fig. 11 shows the results. For example, in the ' 10 day' case (Fig. 11e), an average for a particular month is formed using all the available daily retrievals at locations where there are at least 10 . In addition, a corresponding degraded version of the monthly average is formed by discarding daily retrievals at random so that each average is based upon only 10 values. At locations where at least 63 months (out of 84 ) satisfy the 10 day threshold, remaining months with less than 10 daily retrievals available are filled using linear interpolation between adjacent months. (Increasing the threshold from 63 to 74 reduced the number of grid points available for comparison, but did not change the degree of correlation at the remaining locations.) To increase the number of months containing at least 10 days, the TOMS daily retrievals were screened for clouds using a less stringent 25 percent reflectivity threshold. Within the dust region, this al- 
lows roughly 5 additional retrievals to contribute to any monthly average, so that 15 to 20 daily retrievals are available in an average month. This reflectivity threshold allows the two versions of the monthly anomalies to be correlated at a larger number of grid points, but again didn't affect the agreement at locations containing at least 63 months according to either threshold. At each grid point, the correlation was repeated 50 times, in each case with different days removed at random from the degraded version of the TOMS AI. The correlation in Fig. 11 is the average of the fifty calculations. (The average correlation did not change very much as the number of calculations was increased past 10.)

When the degraded version of the AI is limited to 15 daily retrievals, it remains highly correlated with the monthly anomalies formed from the full TOMS AI data set, suggesting that 15 daily retrievals are sufficient to estimate accurately the monthly average. Similarly, the correlation is high when the degraded version is limited to only 10 days; apparently, the removal of 5 daily retrievals causes only a small change in the monthly average. However, as the number of daily retrievals is reduced to fewer than 10 days, the two versions of the TOMS AI become increasingly decorrelated. If we insist that the original and degraded version of the TOMS AI monthly anomalies have correlation coefficients of at least 0.7 - so that at least half of the variance is shared - then at least 7 daily retrievals are needed to form reliable estimates of the monthly average in the dust region.

In deriving this threshold, we have not assumed or required that the daily images comprising the monthly averages in each version are statistically independent (and thereby separated by three or more days, according to Fig. 6a). Thus, it is possible that the seven daily images used to calculate the degraded monthly averages (Fig. 11d) are not independent. In this case, fewer than seven daily images might be sufficient to derive accurate monthly averages if all the images are independent. Conversely, 7 retrievals bunched together early or late in the month will not be sufficient for a precise estimate of the monthly average, since some of the information contained within the 7 values is redundant.

Fig. 1 shows that while the TOMS AI exceeds the 7 day threshold throughout the dust region - even with the more stringent 15 percent cloud reflectivity criterion - the AVHRR AOT retrievals exceed this threshold only in the northern part of the region. This suggests that the poor correlation of the TOMS AI and AVHRR AOT in the absence of the seasonal cycle is at least partly due to the imprecise estimate of the AOT by AVHRR for any particular month, a result of the limited number of retrievals permitted by the presence of clouds. One means of increasing the number of retrievals available in any particular month is to reconstruct each data set using a coarser grid: that is, trade away spatial resolution in return for increased precision of the monthly averages. We found that we had to increase the size of the AVHRR grid box to $4^{\circ}$ latitude by $5^{\circ}$ longitude
- resolution typical of a climate AGCM - in order to have at least 63 monthly averages of AVHRR comprising at least 10 days in the vicinity of the ITCZ. This is a small increase in retrieval availability given that the new grid was constructed by averaging together 20 AVHRR and 16 TOMS boxes from their original grids; presumably, locations of missing AVHRR data often occur adjacent to each other, which obviates any advantage gained by averaging these points. Nonetheless, the correlation of the two retrievals after removal of the seasonal cycle is increased upon rebinning, as shown in Fig. 12b. This improvement could be interpreted to result from the greater availability of the AVHRR retrieval on the coarser grid. However, the correlation is not increased when restricted to the $\mathrm{NH}$ summer months (Fig. 12d). This is unexpected since the 7 day threshold can be derived by considering only summer months, and suggests that there are additional reasons for the disagreement of the two retrievals at interannual time scales. One possibility is the presence of undetected sub-pixel clouds in the TOMS AI [Torres et al., 1998], although we have not attempted to quantify this effect.

\section{Conclusions}

We compared two estimates of the seasonal cycle and interannual variability of soil dust aerosols, as inferred from the AVHRR AOT and TOMS AI satellite retrievals. Both data sets are attractive to aerosol modelers because of their multi-decadal span and global coverage. We undertook the comparison in order to identify common features of variability that could be used to evaluate the dust distribution calculated by aerosol models, including AGCMs. Each of the retrievals is sensitive to a different aerosol property - reflectance in the case of AVHRR, and absorption for TOMS - and emphasizes different aerosol types. We focused our attention upon the NH subtropical Atlantic Ocean, where soil dust makes the largest contribution to the total aerosol load [Li et al., 1996; Tegen et al., 1997; Chiapello et al., 1999]. Within this region, we assume that soil dust dominates each retrieval, and that the variability associated with sulfate and carbonaceous aerosols is comparatively small. Both retrievals identify the same climatological month corresponding to maximum dust loading, including the variation of this month with latitude. Because the AI varies with the vertical distribution of the aerosol, the amplitude of its seasonal cycle cannot be directly compared with that of the AOT. However, when seasonal variations in the height of the aerosol layer are accounted for, the seasonal cycles of the dust load implied by each retrieval are comparable.

When the seasonal cycle is removed from the monthly averages, the correlation between the two retrievals is sharply reduced. For this comparison, we followed the assumption of [Hsu et al., 1999] that year to year variations in the height of the aerosol layer are of secondary importance to the AI, which thus can be directly compared on interannual time scales to the AOT. In a sep- 
arate study (to be reported upon elsewhere), we tested this assumption by comparing the $\mathrm{AI}$ and dust AOT produced by the Goddard Ozone Chemistry Aerosol Radiation and Transport model (Paul Ginoux, personal communication). This model calculates a realistic spatial distribution of dust aerosols by combining observed winds and precipitation with prescribed dust sources and sinks in a tracer transport model. We found that the monthly averages of the model AI and dust AOT are almost perfectly correlated, after the removal of the seasonal cycle. That is, while variations in aerosol height contribute strongly to the AI on daily and seasonal time scales, interannual variations of the $\mathrm{AI}$ are dominated by variations of the AOT.

The poor interannual agreement is in contrast to the substantially larger correlation that results when the monthly anomalies are constructed using only days common to the two retrievals. This consistency suggests that both the TOMS AI and AVHRR AOT accurately estimate the aerosol load of any particular scene. However, because clouds limit the availability of the AVHRR AOT retrieval to a greater extent than the TOMS AI, its monthly averages have a potentially larger uncertainty. We suggest that this uncertainty is partly responsible for the poor interannual correlation, when the monthly anomalies are constructed using all available daily observations. We estimated how many daily retrievals were needed to form a reliable estimate of the monthly average by correlating two versions of the TOMS AI monthly anomalies. The anomalies in one version were constructed using all the available data, typically 15 or more retrievals per month within the dust region. In the other version, a certain number of observations were discarded so that the monthly anomaly was estimated with greater uncertainty. When the degraded version was constructed with fewer than 7 to 10 retrievals per month, the correlation with the original TOMS AI was quite low. This suggests that estimates of interannual variations of soil dust transport over the Atlantic require roughly at least 7 retrievals per month. An additional constraint results from the 3 day decorrelation time of dust, so that the 7 retrievals must not represent consecutive days. Only the TOMS AI is able to exceed this threshold, due to its greater ability to retrieve the aerosol load in the presence of clouds. Whether it should be regarded as a more reliable indicator of interannual variability depends upon the importance of undetected sub-pixel clouds [Torres et al., 1998]. This is potentially a more serious limitation of TOMS, due to the instrument's relatively large footprint, although we did not quantify this effect. In any case, both TOMS and AVHRR should be capable of accurately estimating the seasonal cycle, since seven years provide sufficient observations necessary to form the climatological mean of any calendar month.

In order to increase the number of AVHRR AOT retrievals available during any particular month, we rebinned the data onto a coarser grid. This resulted in an improved correlation with the TOMS AI, which we inter- preted as due to the increased precision of the AVHRR monthly averages. In addition, spatial averages of each retrieval over the dust region showed a higher interannual correlation, compared to the correlation at individual grid points (c.f. Fig. 7c versus 8 b). This suggests that there is intrinsic agreement between the TOMS AI and AVHRR AOT that is mainly obscured by the sampling uncertainty of the latter. That is, sub-pixel cloud contamination may be of lesser importance. However, there was almost no agreement when the comparison of spatial averages was restricted to the summer months. Similarly, rebinning did not improve the summertime correlation. Sub-pixel contamination by clouds may be particularly important during this season, when mesoscale and synoptic variations of cloud cover associated with African waves is largest.

The high correlation of scenes common to the TOMS AI and AVHRR AOT suggest that current estimates of interannual aerosol variability are limited not by lack of precision of either retrieval within individual scenes, but rather by the insufficient number of AVHRR retrievals needed to estimate accurate monthly averages and thus month to month variability. However, the availability of the AVHRR AOT is not far below the seven-day threshold that we estimated; only a few more daily retrievals per month could make a large improvement. This might result if a more precise cloud screening algorithm could exclude fewer scenes. In addition, the uncertainty of the TOMS AI could be reduced by quantifying the effect of sub-pixel clouds. In the meantime, the disagreement between the two retrievals at interannual time scales might be adjudicated using Meteosat retrievals [Moulin et al., 1997b], which despite their restricted areal coverage, include our dust region. In addition, a more precise comparison of the annual cycle of dust loading may be possible using TOMS AOT retrievals that incorporate information on aerosol height more precisely and systematically than we have done here [Torres et al., 1998].

The limited interannual correlation may also indicate the presence in each data set of variability by other aerosol types. In addition to dust, AVHRR retrievals may include industrial sulfates, carbonaceous aerosols, and sea salt, while TOMS may include carbonaceous aerosols. We tried to minimize this difference by limiting our study to the NH subtropical Atlantic Ocean, where we expect soil dust to be the dominant source of aerosol variability [Chiapello et al., 1999]. The introduction of polarization measurements in the retrieval will make available additional information, such as the particle index of refraction or Angstrom coefficient, that can identify the aerosol type [Mishchenko and Travis, 1997; Chiapello et al., 2000]. Similarly, two-channel AVHRR will replace assumptions about aerosol particle size with inferences derived from the additional channel [Mishchenko et al., 2000].

Despite the limited variance shared by the two retrievals at interannual time scales, the seasonal cycle of dust loading, for which both data sets agree, can be 
used to constrain dust models. Certain global models of aerosols underestimate in comparison to the AVHRR AOT the summertime maximum of soil dust transported downwind from the Sahara [Tegen et al., 1997; Perlwitz et al., 2000]; for these models, the agreement of the seasonal cycle between the two retrievals is more immediately relevant than the uncertain estimates of interannual variability. Future retrieval products will lead to stronger constraints on model interannual behavior. Light Detection And Ranging (LIDAR) observations will provide complementary information on the vertical distribution, which is crucial to the climate effect of aerosols [Miller and Tegen, 1999]. Together, these observations will lead to more confident predictions on the importance of aerosols in forcing climate and climate change.

Acknowledgments We thank Jay Herman, David Larko, and Larry Stowe for providing the TOMS and AVHRR retrievals and guidance concerning their use. Paul Ginoux provided GOCART model output, which helped us to interpret the correlation of the monthly anomalies. Paul Ginoux, Omar Torres, and three reviewers, including Larry Stowe, provided comments that substantially improved this article. We also benefited from conversations with Brian Cairns, Carl Delo, Rudolph Husar, Michael Mishchenko, William Rossow, and Clark Weaver. This work was supported by the Climate Dynamics Program of the National Science Foundation (ATM-97-27872) and the Atlantic Climate Change Program of the National Oceanic and Atmospheric Administration (NA86GP0556).

\section{References}

Andreae, M., Climatic effects of changing atmsopheric levels, in World survey of climatology, vol. 16, Future of the world, edited by Henderson-Sellers, Elsevier, 1995.

Carlson, T. N., and J. M. Prospero, The large-scale movement of Saharan air outbreaks over the northern equatorial Atlantic, J. Appl. Meterol., 11, 283-297, 1972 .

Charlson, R., S. Schwartz, J. Hales, R. Cess, J. Coakley, J. Hansen, and D. Hofman, Climate forcing by anthropogenic aerosols, Science, 255, 423-430, 1992.

Chiapello, I., G. Bergametti, L. Gomes, B. Chatenet, F. Dulac, J. Pimenta, and E. Santos Suarez, An additional low layer transport of Sahelian and Saharan dust over the north-eastern tropical Atlantic, Geophys. Res. Lett., 22, 3191-3194, 1995.

Chiapello, I., G. Bergametti, C. B., F. Dulac, I. Jankowiak, C. Liousse, and E. Soares, Contribution of the different aerosol species to the aerosol mass load an optical depth over the northeastern tropical Atlantic, J. Geophys. Res., 104, 4025-4035, 1999.

Chiapello, I., P. Goloub, G. Tanre, A. Marchand, J. Herman, and $O$. Torres, Aerosol detection by TOMS and POLDER over oceanic regions, J. Geophys. Res., 105, 7133-7142, 2000.

Duce, R., Sources, distributions, and fluxes of mineral aerosols and their relationship to climate change, in
Aerosol Forcing of Climate, pp. 43-72, John Wiley and Sons Ltd, 1995.

Hansen, J., M. Sato, A. Lacis, R. Ruedy, I. Tegen, and E. Matthews, Climate forcings in the industrial era, Proc. Natl. Acad. Sci., 95, 12,753-12,758, 1998.

Hansen, J., R. Ruedy, J. Glascoe, and M. Sato, GISS analysis of surface temperature change, $J$. Geophys. Res., 104, 30,997-31,022, 1999.

Herman, J. R., P. K. Bhartia, O. Torres, C. Hsu, C. Seftor, and E. Celarier, Global distribution of UVabsorbing aerosols from Nimbus-7/TOMS data, $J$. Geophys. Res., 102, 16,911-16,922, 1997.

Houghton, J., L. Meira Filho, B. Callander, N. Harris, K. A., and M. K., Climate Change 1995: The IPCC Scientific Assessment, Cambridge University Press, 1996.

Hsu, N., J. Herman, O. Torres, B. Holben, D. Tanre, T. Eck, A. Smirnov, B. Chatenet, and F. Lavenu, Comparisons of the TOMS aerosol index with Sunphotometer aerosol optical thickness: Results and applications, J. Geophys. Res., 104, 6269-6279, 1999.

Husar, R. B., J. M. Prospero, and L. L. Stowe, Characterization of tropospheric aerosols over the oceans with the NOAA Advanced Very High Resolution Radiometer optical thickness operational product, $J$. Geophys. Res., 102, 16,889-16,909, 1997.

Ignatov, A., L. Stowe, S. Sakerin, and G. Korotaev, Validation of the NOAA/NESDIS satellite aerosol product over the North Atlantic in 1989, J. Geophys. Res., $100,5123-5132,1995$.

King, M., Y. Kaufman, D. Tanre, and T. Nakajima, Remote sensing of tropospheric aerosols from space: past, present, and future, Bull. Amer. Meteor. Soc., 11, 2229-2259, 1999.

Li, X., H. Maring, D. Savoie, K. Voss, and J. M. Prospero, Dominance of mineral dust in aerosol lightscattering in the North Atlantic trade winds, Nature, $380,416-419,1996$.

Miller, R., and I. Tegen, Climate response to soil dust aerosols, J. Climate, 11, 3247-3267, 1998.

Miller, R. L., and I. Tegen, Radiative forcing of a tropical direct circulation by soil dust aerosols, J. Atmos. Sci., $56,2403-2433,1999$.

Mishchenko, M., and L. Travis, Satellite retrieval of aerosol properties over the ocean using polarization as well as intensity of reflected sunlight, J. Geophys. Res., 102, 16,989-17,013, 1997.

Mishchenko, M., A. Lacis, B. Carlson, and L. Travis, Nonsphericitiy of dust-like tropospheric aerosols: implications for aerosol remote sensing and climate, Geophys. Res. Lett., 22, 1077-1080, 1995.

Mishchenko, M. I., I. V. Geogdzhayev, B. Cairns, W. B. Rossow, and A. A. Lacis, Aerosol retrievals over the ocean by use of channels 1 and 2 AVHRR data: sensitivity analysis and preliminary results, Appl. Opt., $38,7325-7341,2000$.

Moulin, C., F. Dulac, C. Lambert, P. Chazette, I. Jankowiak, B. Chatenet, and F. Lavenu, Longterm daily monitoring of Saharan dust load over ocean using Meteosat ISCCP-B2 data, 2, accuracy 
of the method and validation using Sun photometer measurements, J. Geophys. Res., 102, 16,959-16,969, $1997 a$.

Moulin, C., F. Guillard, F. Dulac, and C. Lambert, Long-term daily monitoring of Saharan dust load over ocean using Meteosat ISCCP-B2 data, 1, methodology and preliminary results for 1983-1994 in the Mediterranean, J. Geophys. Res., 102, 16,947-16,958, $1997 \mathrm{~b}$.

Moulin, C., C. E. Lambert, F. Dulac, and U. Dayan, Control of atmospheric export of dust from North Africa by the North Atlantic Oscillation, Nature, 387 , 691-693, 1997c.

Perlwitz, J., I. Tegen, and R. L. Miller, Interactive soil dust aerosol model in the GISS GCM. part I: Sensitivity of the soil dust cycle to radiative properties of soil dust aerosols, J. Geophys. Res., 2000, (accepted).

Prospero, J. M., and R. T. Nees, Impact of North African drought and El Niño on mineral dust in the Barbados trade winds, Nature, 320,735-738, 1986.

Prospero, J. M., R. A. Glaccum, and R. T. Nees, Atmospheric transport of soil dust from Africa to South America, Nature, 289, 570-572, 1981.

Stowe, L., A. Ignatov, and R. Singh, Development, validation, and potential enhancements to the secondgeneration operational aerosol product at the $\mathrm{Na}$ tional Environmental Satellite, Data, and Information Service of the National Oceanic and Atmospheric Administration, J. Geophys. Res., 102, 16,923-16,934, 1997.

Swap, R., S. Ulanski, M. Cobbett, and M. Garstang, Temporal and spatial characteristics of Saharan dust outbreaks, J. Geophys. Res., 101, 4205-4220, 1996.

Tegen, I., and I. Fung, Modeling of mineral dust in the atmosphere: Sources, transport, and optical thickness, J. Geophys. Res., 99, 22,897-22,914, 1994.

Tegen, I., and I. Fung, Contribution to the atmospheric mineral aerosol load from land surface modification, J. Geophys. Res., 100, 18,707-18,726, 1995.

Tegen, I., and A. A. Lacis, Modeling of particle influence on the radiative properties of mineral dust aerosol, $J$. Geophys. Res., 101, 19,237-19,244, 1996.

Tegen, I., and R. Miller, A general circulation model study on the interannual variability of soil dust aerosol, J. Geophys. Res., 103, 25,975-25,995, 1998.

Tegen, I., A. A. Lacis, and I. Fung, The influence on climate forcing of mineral aerosols from disturbed soils, Nature, 380, 419-422, 1996.

Tegen, I., P. Hollrig, M. Chin, I. Fung, D. Jacob, and J. Penner, Contribution of different aerosol species to the global aerosol extinction optical thickness: Estimates from model results, J. Geophys. Res., 102, $23,89523,915,1997$.

Torres, O., J. Bhartia, J. Herman, Z. Ahmad, and J. Gleason, Derivation of aerosol properties from satellite measurements of backscattered ultraviolet radiation: Theoretical basis, J. Geophys. Res., 103, 17,099-17,110, 1998.

Reha Cakmur, NASA GISS, 2880 Broadway, NYC, NY 10025 (e-mail: rcakmur@giss.nasa.gov)
This preprint was prepared with AGU's IATEX macros v5.01, with the extension package ' $\mathrm{AGU}^{++}$' by $\mathrm{P}$. W. Daly, version $1.6 \mathrm{~b}$ from $1999 / 08 / 19$. 


\section{Figure Captions}

Fig. 1: Average number of daily retrievals available per month from 1984 to 1990 for a) TOMS AI and b) AVHRR AOT.

Fig. 2: Climatological average of the TOMS AI and AVHRR AOT retrievals. a) Annual mean TOMS AI, b) annual mean AVHRR AOT, c) NH summer (June-September) mean TOMS AI, and d) NH summer (June-September) mean AVHRR AOT.

Fig. 3: Seasonal cycle of the a) TOMS AI and b) AVHRR AOT, averaged zonally across the NH subtropical Atlantic from $40.5^{\circ} \mathrm{W}$ to $18.125^{\circ} \mathrm{W}$ longitude (near the African coast).

Fig. 4: Seasonal cycle of the ratio of the TOMS AI and AVHRR AOT, averaged at $15.5^{\circ} \mathrm{N}$ between the longitudes of Dakar and Sal, Cape Verde Islands.

Fig. 5: Standard deviation of the TOMS AI and AVHRR AOT monthly average retrievals with the seasonal cycle removed. a) entire year, TOMS AI, b) entire year AVHRR AOT, c) NH summer (June-September) TOMS AI, and d) NH summer (June-September) AVHRR AOT.

Fig. 6: a) Autocorrelation as a function of lag for the TOMS AI. The 1988 AI daily retrievals were high-pass filtered to remove frequencies higher than 30 days. The autocorrelation is averaged over the dust region. (At any individual location, the function is quite similar.) b) Number of indepedent observations available each month for the TOMS AI, and c) AVHRR AOT. The number of indepedent observations was computed by counting successive daily images within each month separated by three or more days.

Fig. 7: a) Spatial average within the dust region of the TOMS AI (solid) and AVHRR AOT (dotted) monthly averages. For ease of comparison, the spatial average of each data set has been normalized to have zero mean and unit standard deviation over the 84-month period. b) Seasonal cycle of the spatial average of each data set, c) Monthly anomalies of the spatial average computed by removing the seasonal cycle from the monthly averages in (a). Values corresponding to NH summer months (June-September) are denoted by thicker lines.

Fig. 8: Correlation of TOMS AI and AVHRR AOT a) including the seasonal cycle, b) with the seasonal removed, c) restricted to the summer months, but including the seasonal cycle, d) restricted to the summer months, with the seasonal cycle removed. The $95 \%, 99 \%$, and $99.9 \%$ confidence levels are a, b) $0.21,0.28,0.35$, and $c, d$ ) $0.37,0.47$, 0.58. The correlation is computed at locations where at least 63 months have 3 or more daily retrievals; otherwise, the location is denoted by a dot.

Fig. 9: As in Fig. 8, but with the monthly averages of each retrieval computed using only the days when both retrievals are available.

Fig. 10: The number of days during any particular month when both retrievals are available at a grid point, averaged over the dust region.

Fig. 11: Correlation (after removal of the seasonal cycle) of monthly averages of the TOMS AI with a 'degraded' version of the TOMS AI where monthly averages are formed after discarding daily retrievals at random. Daily retrievals are discarded until the degraded version has a) 1 , b) 3 , c) 5 , d) 7 , e) 10 , f) 15 retrievals available to form the monthly average. Correlations are computed at locations where at least 63 months have the minimum number of daily retrievals: e.g. in panel e, this minimum is 10 . Otherwise, the location is marked in yellow.

Fig. 12: As in Fig. 8, but with both the TOMS and AVHRR AOT rebinned onto a $4^{\circ}$ latitude by $5^{\circ}$ grid. Each monthly average is formed with at least 10 daily retrievals. 
a) Average no. of days in a month, TOMS

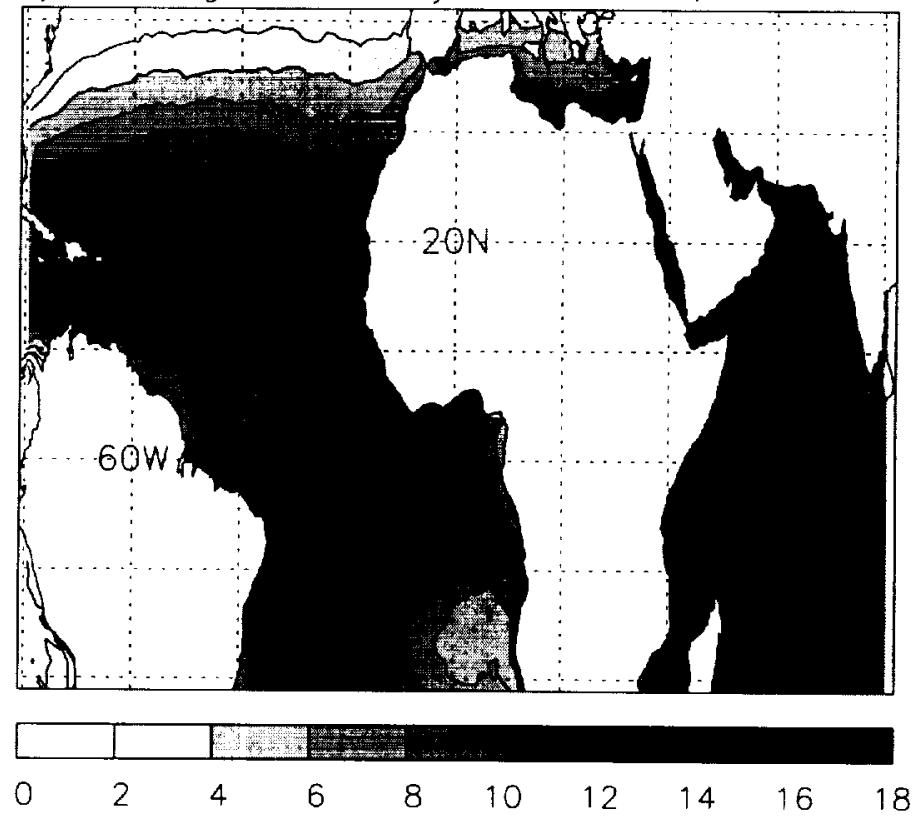

b) Average no. of days in a month, AVHRR

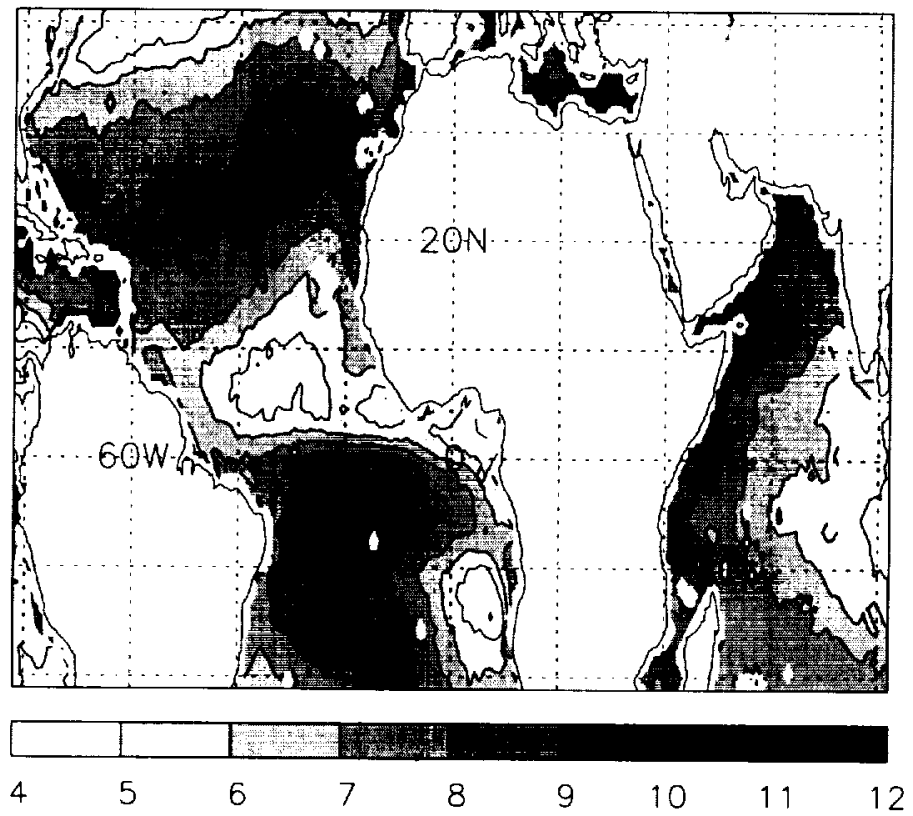

Figure 1. Average number of daily retrievals available per month from 1984 to 1990 for a) TOMS AI and b) AVHRR AOT. 
a) Annual mean TOMS (84-90)

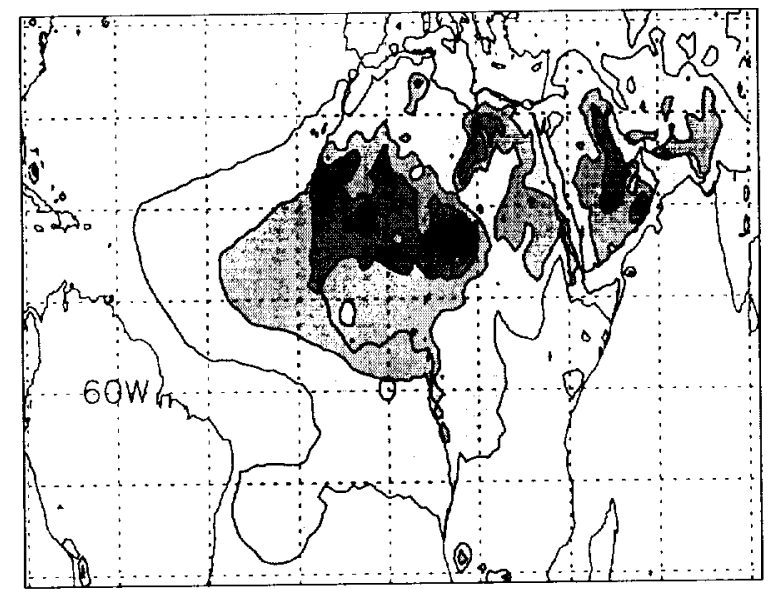

c) JUAS mean TOMS (84-90)

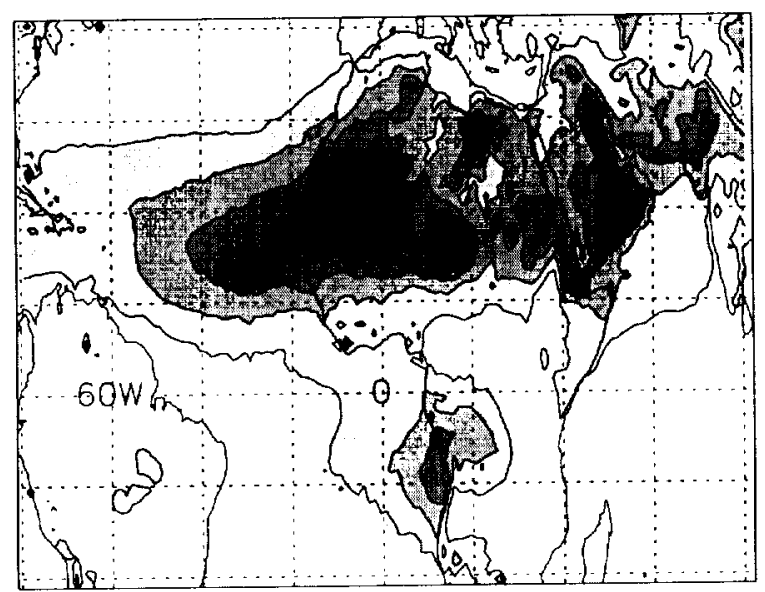

b) Annual meon AVHRR (84-90)

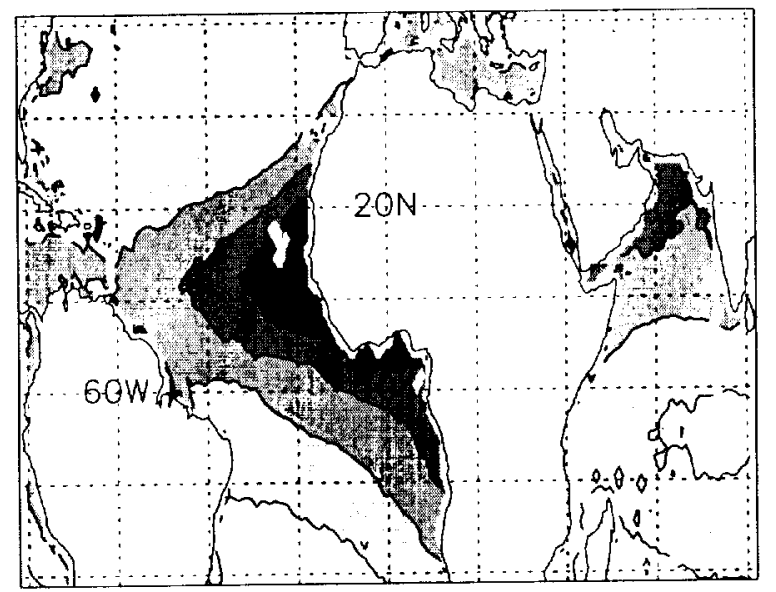

d) JJAS mean AVHRR (84-90)

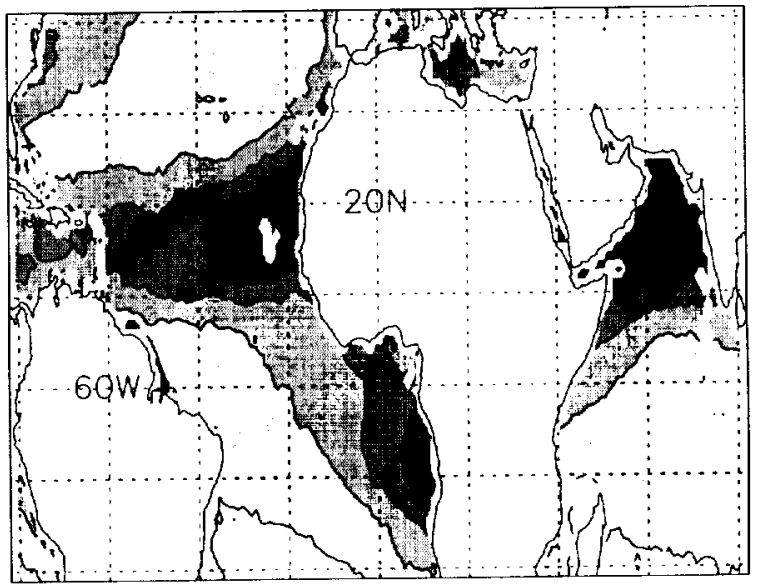

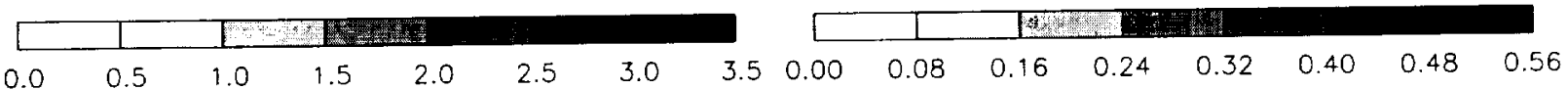

Figure 2. Climatological average of the TOMS AI and AVHRR AOT retrievals. a) Annual mean TOMS AI, b) annual mean AVHRR AOT, c) NH summer (June-September) mean TOMS AI, and d) NH summer (June-September) mean AVHRR AOT. 

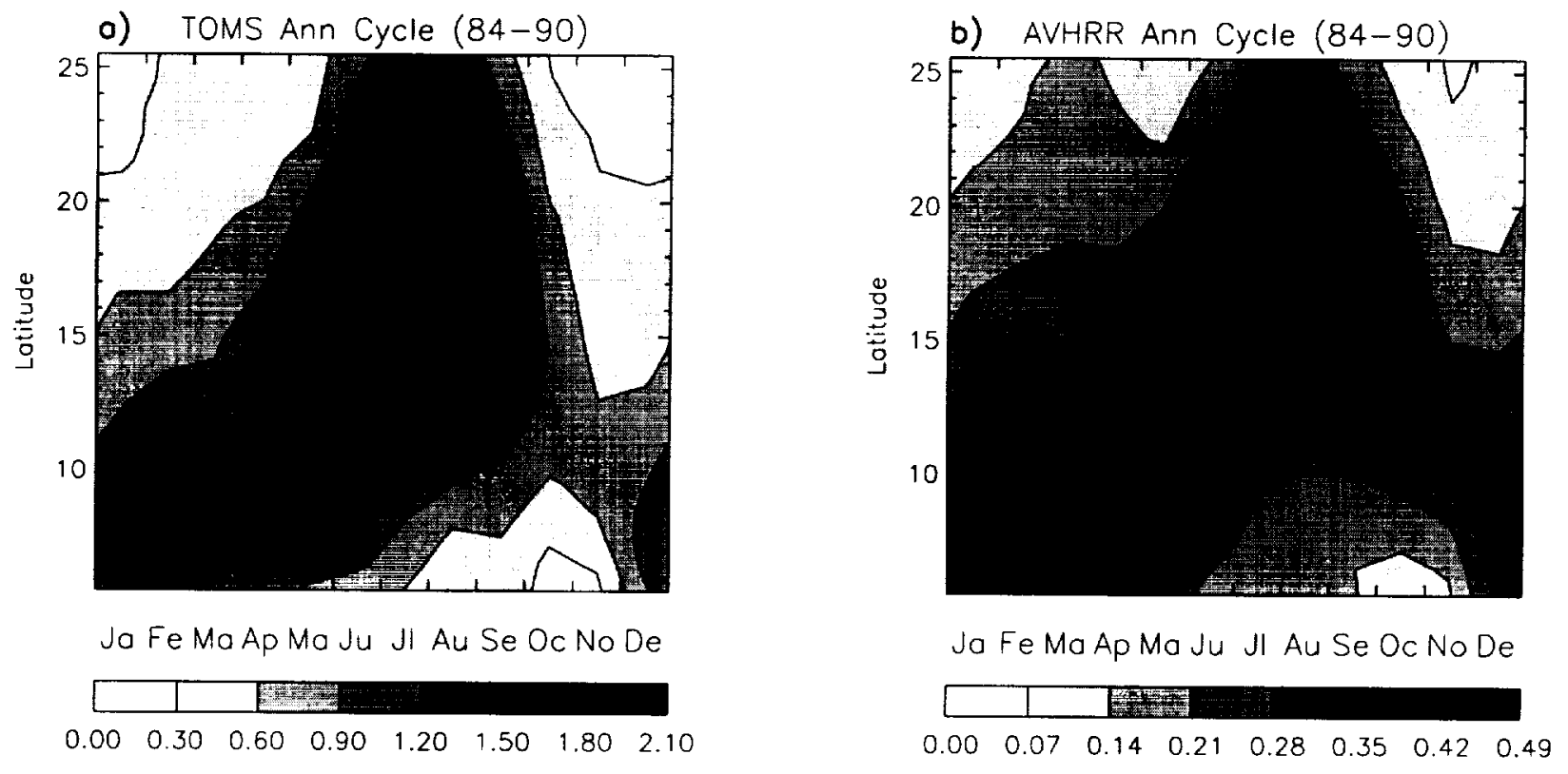

Figure 3. Seasonal cycle of the a) TOMS AI and b) AVHRR AOT, averaged zonally across the NH subtropical Atlantic from $40.5^{\circ} \mathrm{W}$ to $18.125^{\circ} \mathrm{W}$ longitude (near the African coast). 


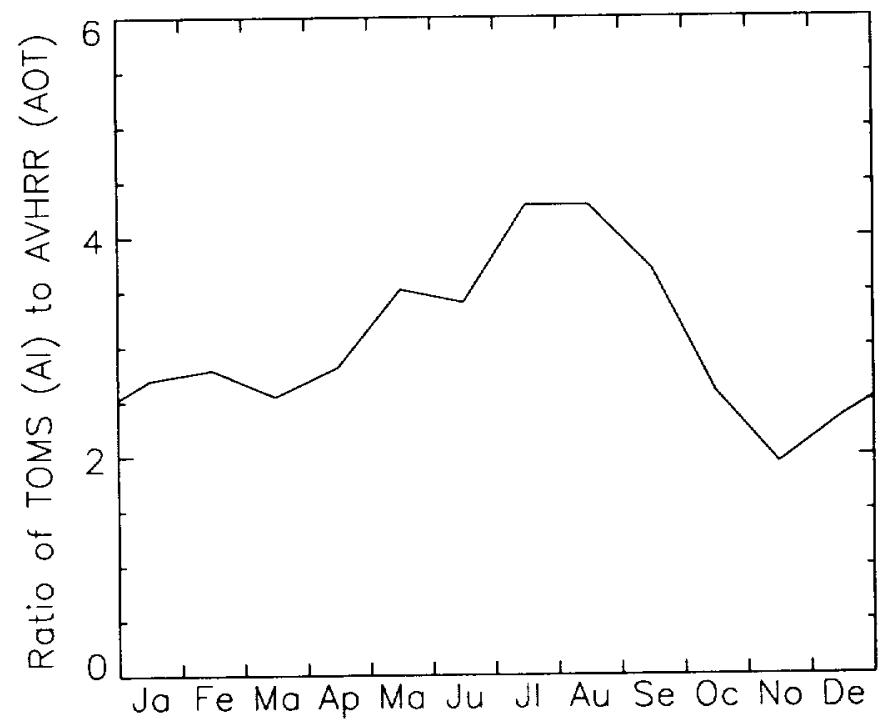

Figure 4. Seasonal cycle of the ratio of the TOMS AI and AVHRR AOT, averaged at $15.5^{\circ} \mathrm{N}$ between the longitudes of Dakar and Sal, Cape Verde Islands. 
a) Annual Std. Dev. TOMS (84-90)

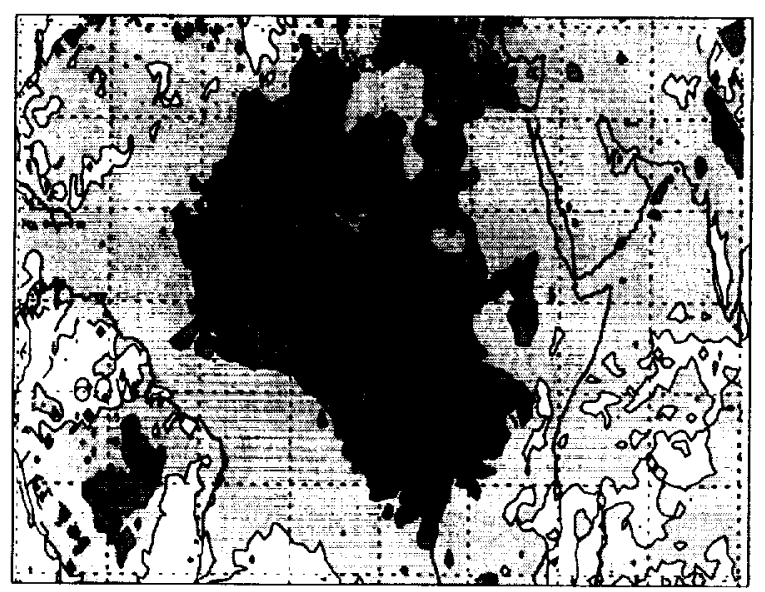

c) JJAS Std. Dev. TOMS (84-90)

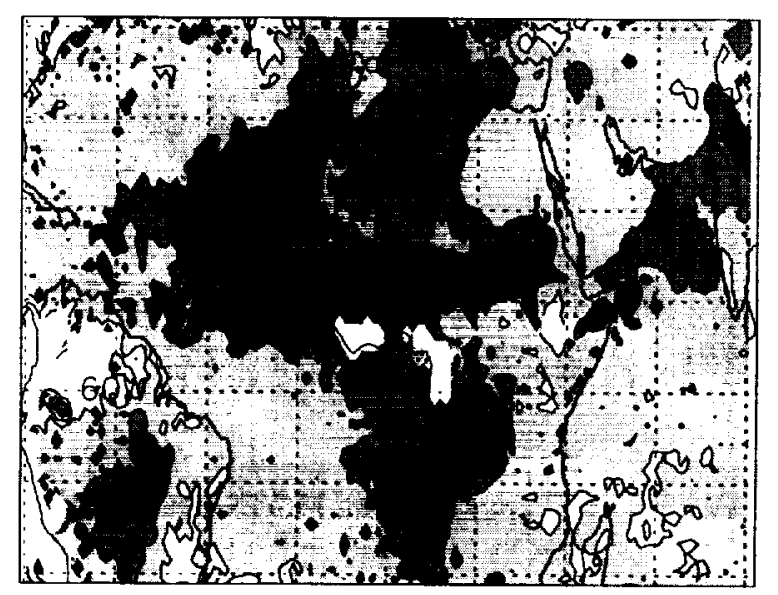

b) Annual Std. Dev. AVHRR (84-90)

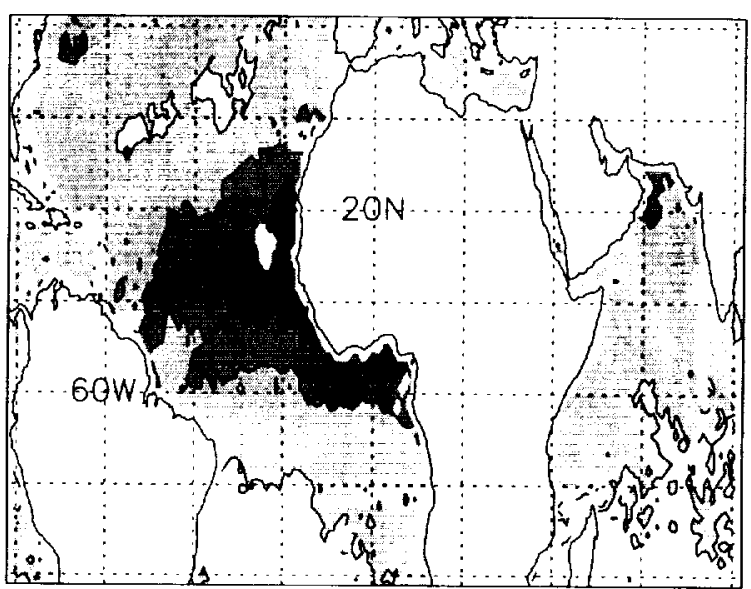

d) JJAS Std. DeV. AVHRR (84-90)

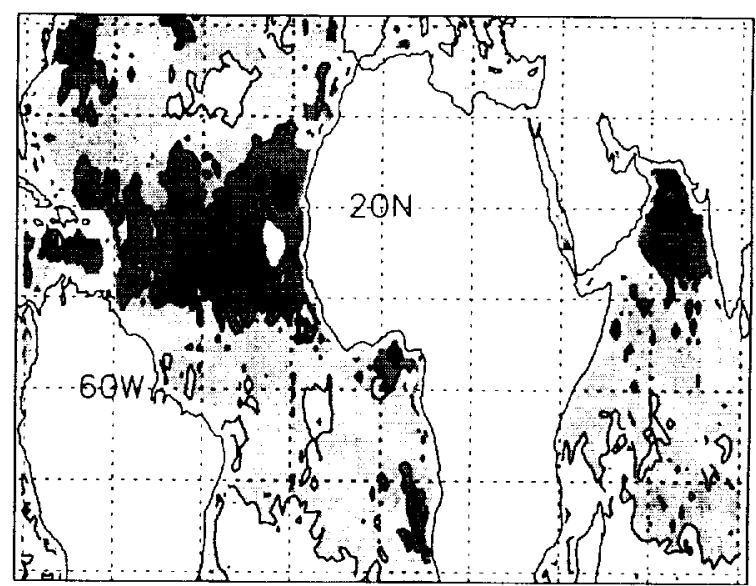

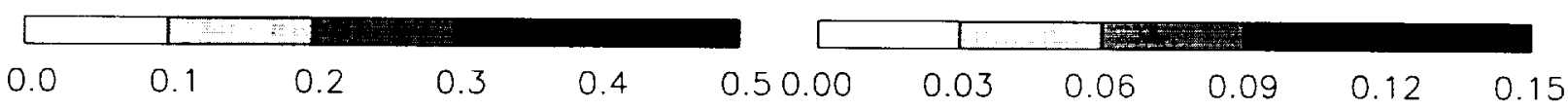

Figure 5. Standard deviation of the TOMS AI and AVHRR AOT monthly average retrievals with the seasonal cycle removed. a) entire year, TOMS AI, b) entire year AVHRR AOT, c) NH summer (JuneSeptember) TOMS AI, and d) NH summer (June-September) AVHRR AOT. 

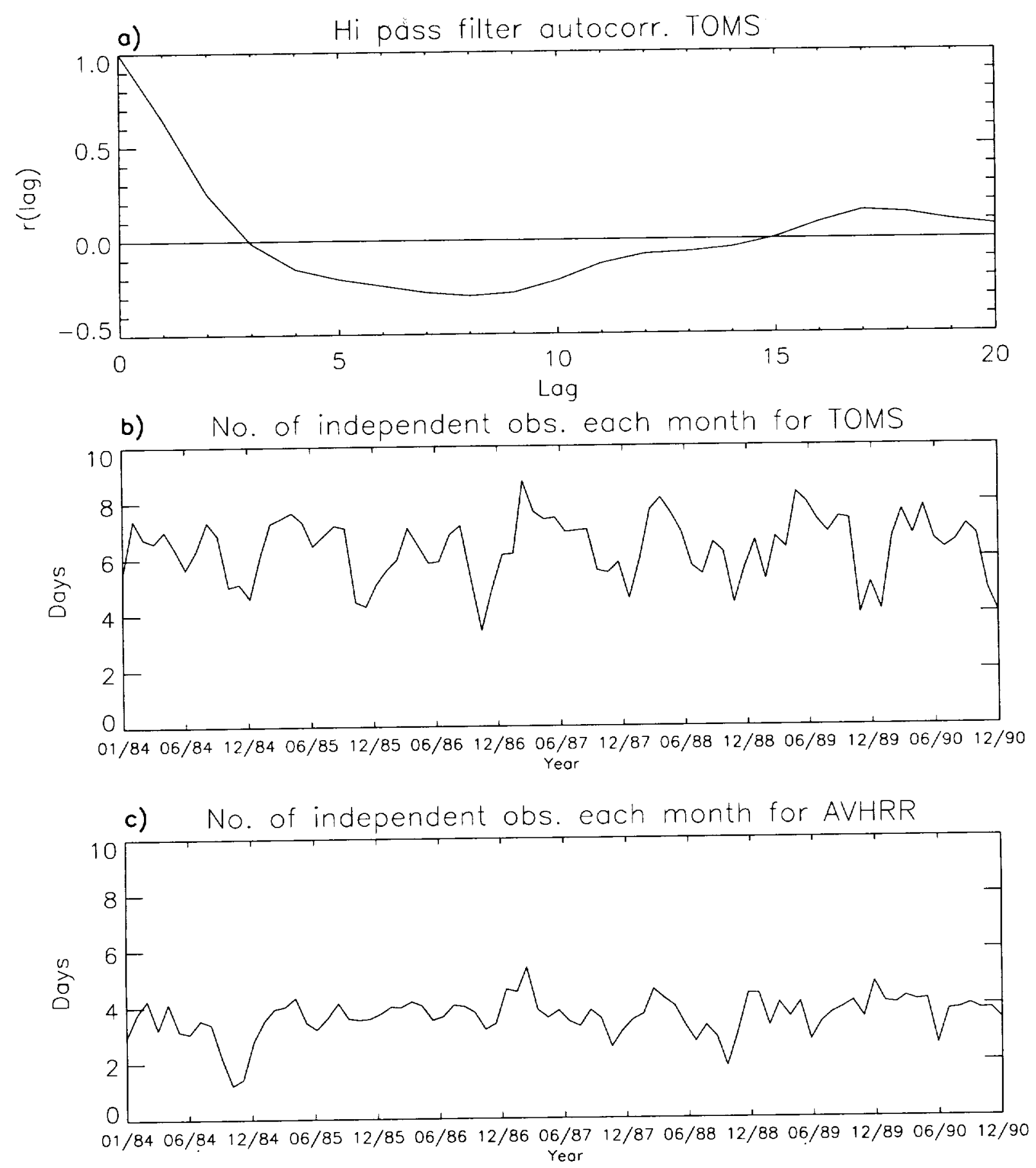

Figure 6. a) Autocorrelation as a function of lag for the TOMS AI. The 1988 AI daily retrievals were high-pass filtered to remove frequencies higher than 30 days. The autocorrelation is averaged over the dust region. (At any individual location, the function is quite similar.) b) Number of indepedent observations available each month for the TOMS AI, and c) AVHRR AOT. The number of indepedent observations was computed by counting successive daily images within each month separated by three or more days. 

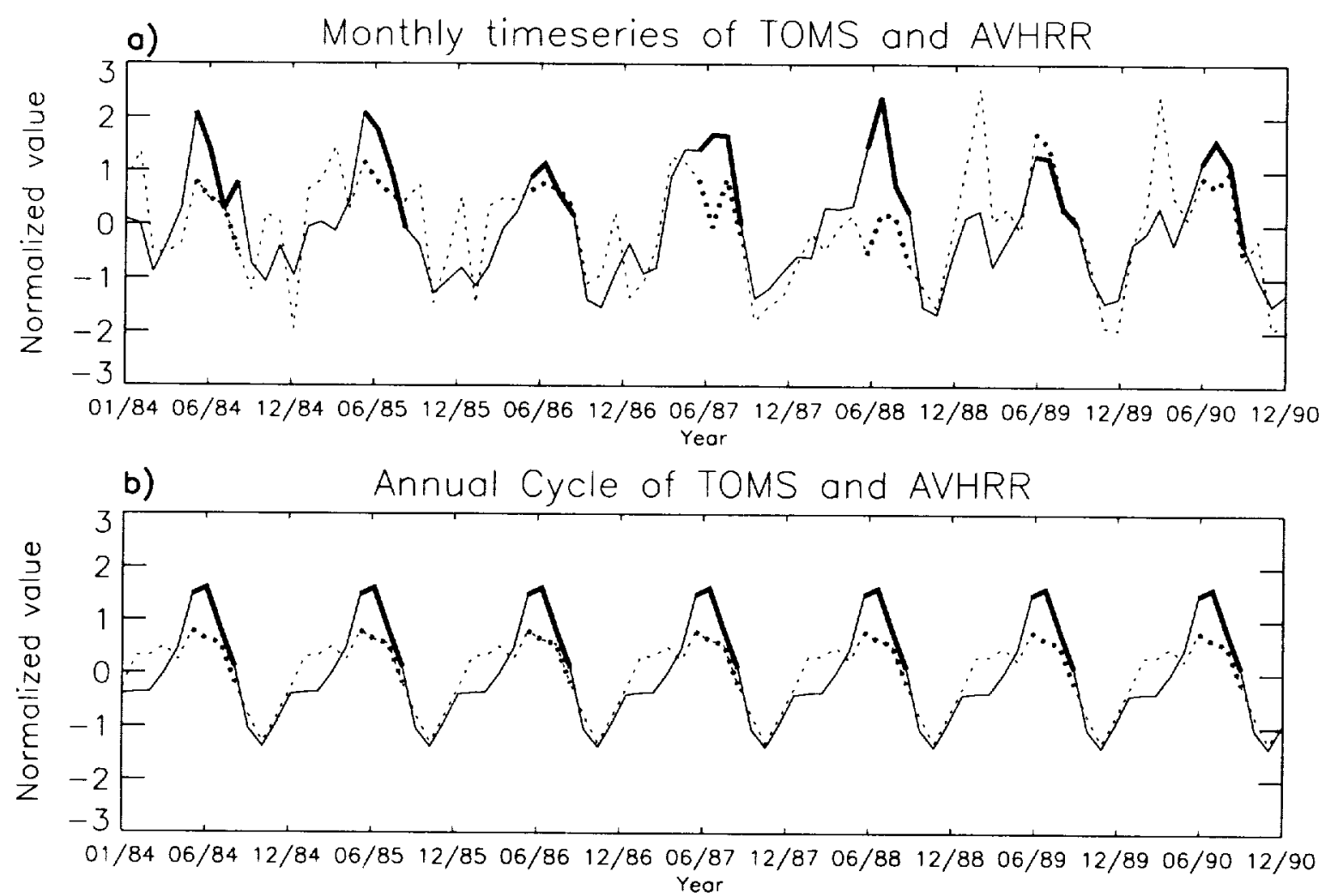

c)

TOMS and AVHRR, without annual cycle

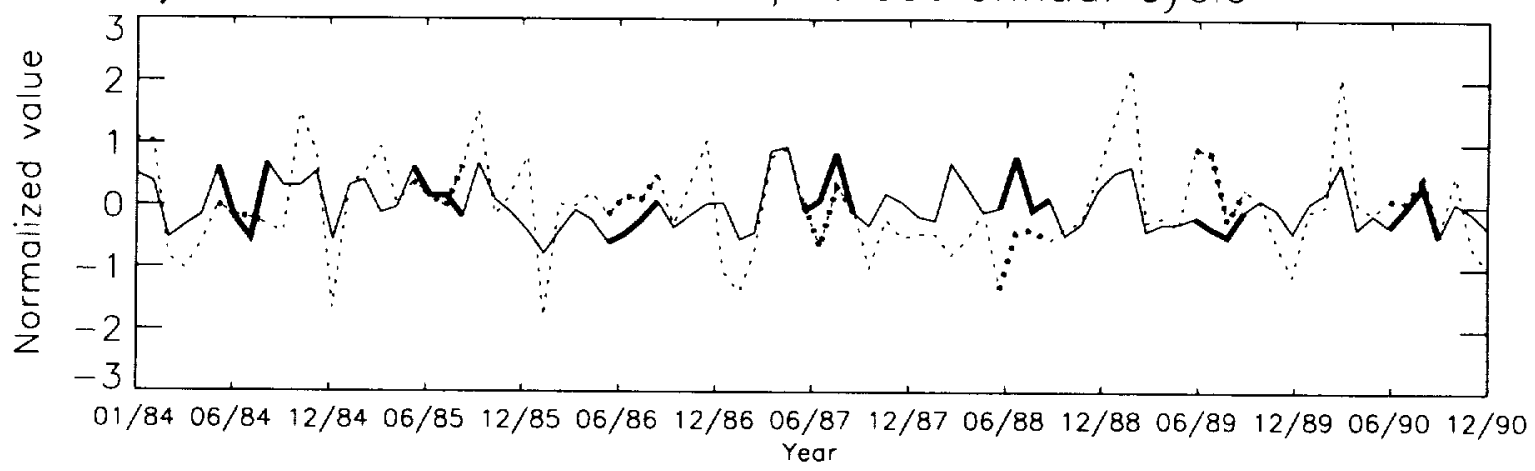

Figure 7. a) Spatial average within the dust region of the TOMS AI (solid) and AVHRR AOT (dotted) monthly averages. For ease of comparison, the spatial average of each data set has been normalized to have zero mean and unit standard deviation over the 84-month period. b) Seasonal cycle of the spatial average of each data set, c) Monthly anomalies of the spatial average computed by removing the seasonal cycle from the monthly averages in (a). Values corresponding to NH summer months (June-September) are denoted by thicker lines. 
a) Including Annual Cycle (All Months)

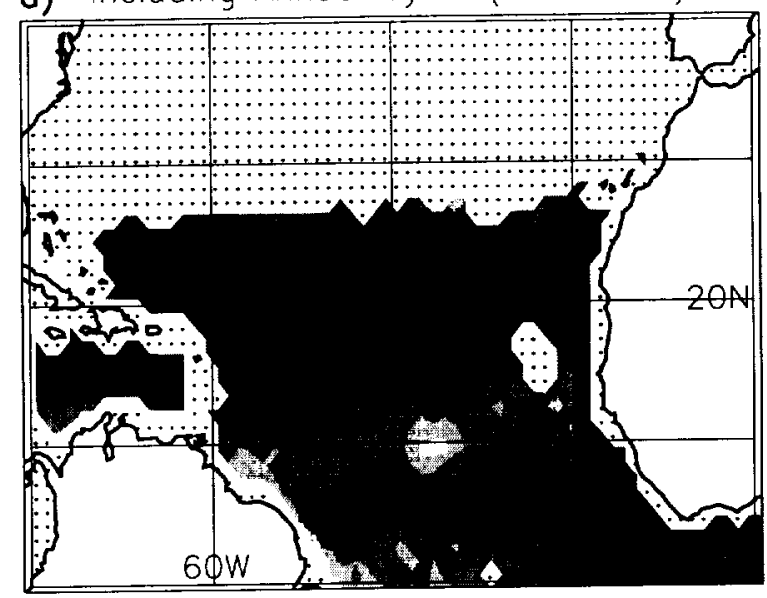

b) Without Annual Cycle (All Months)

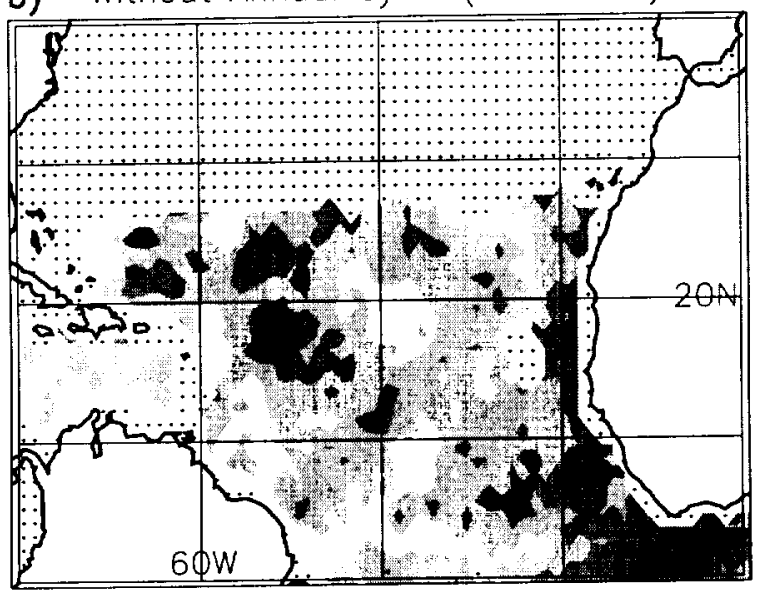

c) Including Annual Cycle (JJAS)

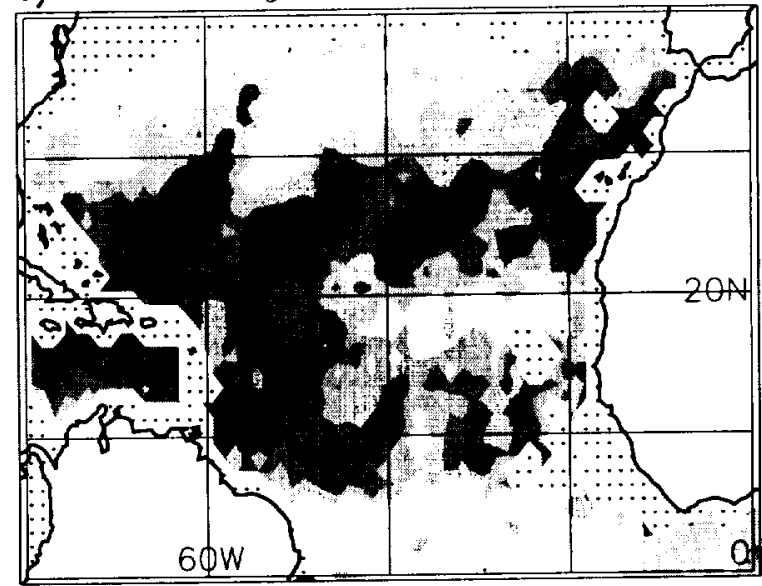

d) Without Annual Cycle (JJAS)

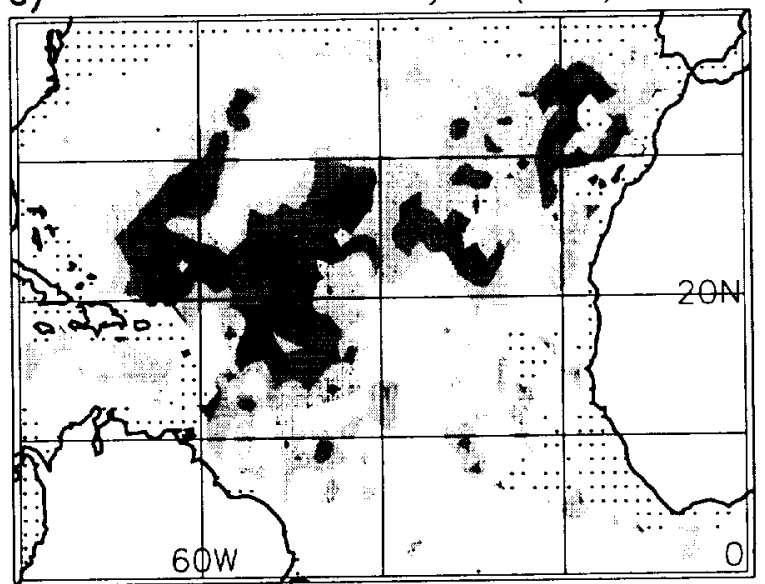

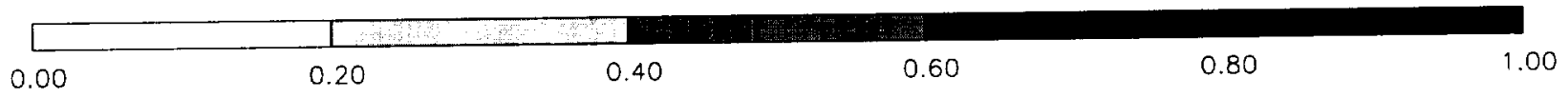

Figure 8. Correlation of TOMS AI and AVHRR AOT a) including the seasonal cycle, b) with the seasonal removed, c) restricted to the summer months, but including the seasonal cycle, d) restricted to the summer months, with the seasonal cycle removed. The $95 \%, 99 \%$, and $99.9 \%$ confidence levels are a, b) $0.21,0.28$, 0.35 , and $c, d$ ) $0.37,0.47,0.58$. The correlation is computed at locations where at least 63 months have 3 or more daily retrievals; otherwise, the location is denoted by a dot. 

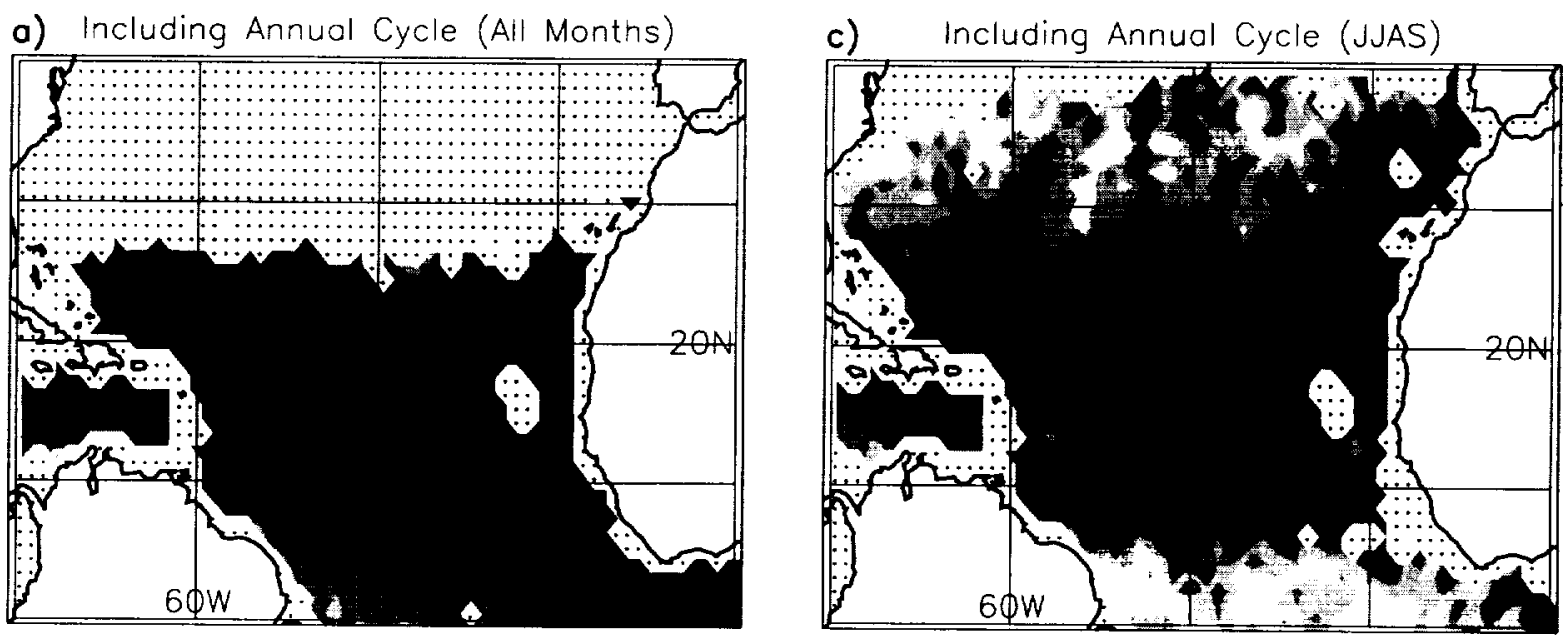

b) Without Annual Cycle (All Months)

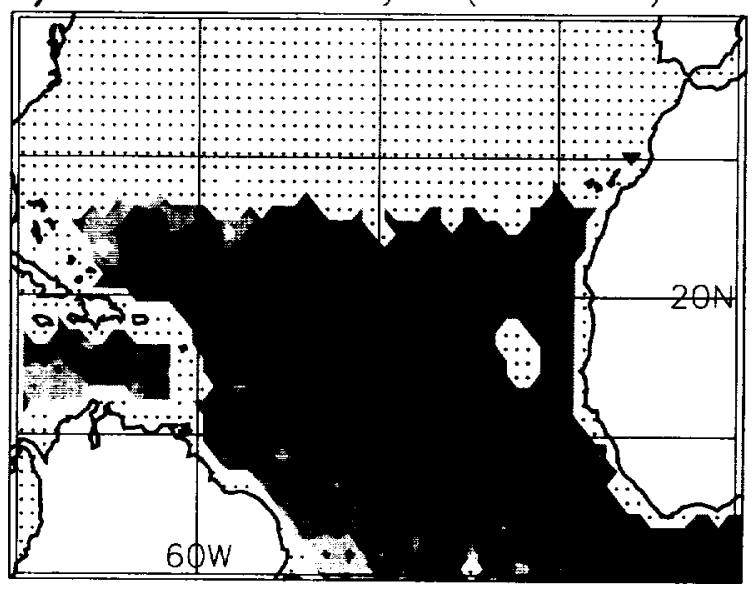

d) Without Annual Cycle (JJAS)
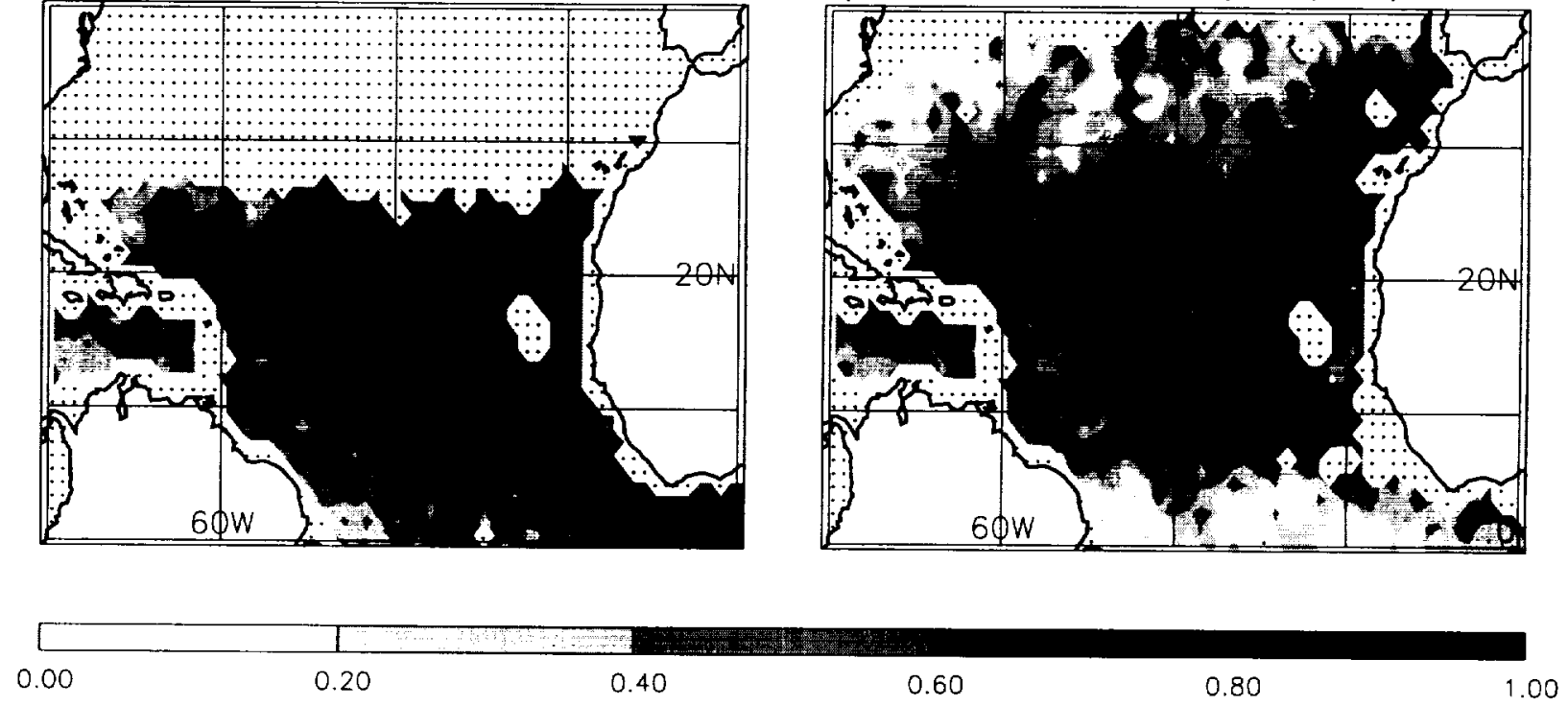

Figure 9. As in Fig. 8, but with the monthly averages of each retrieval computed using only the days when both retrievals are available. 


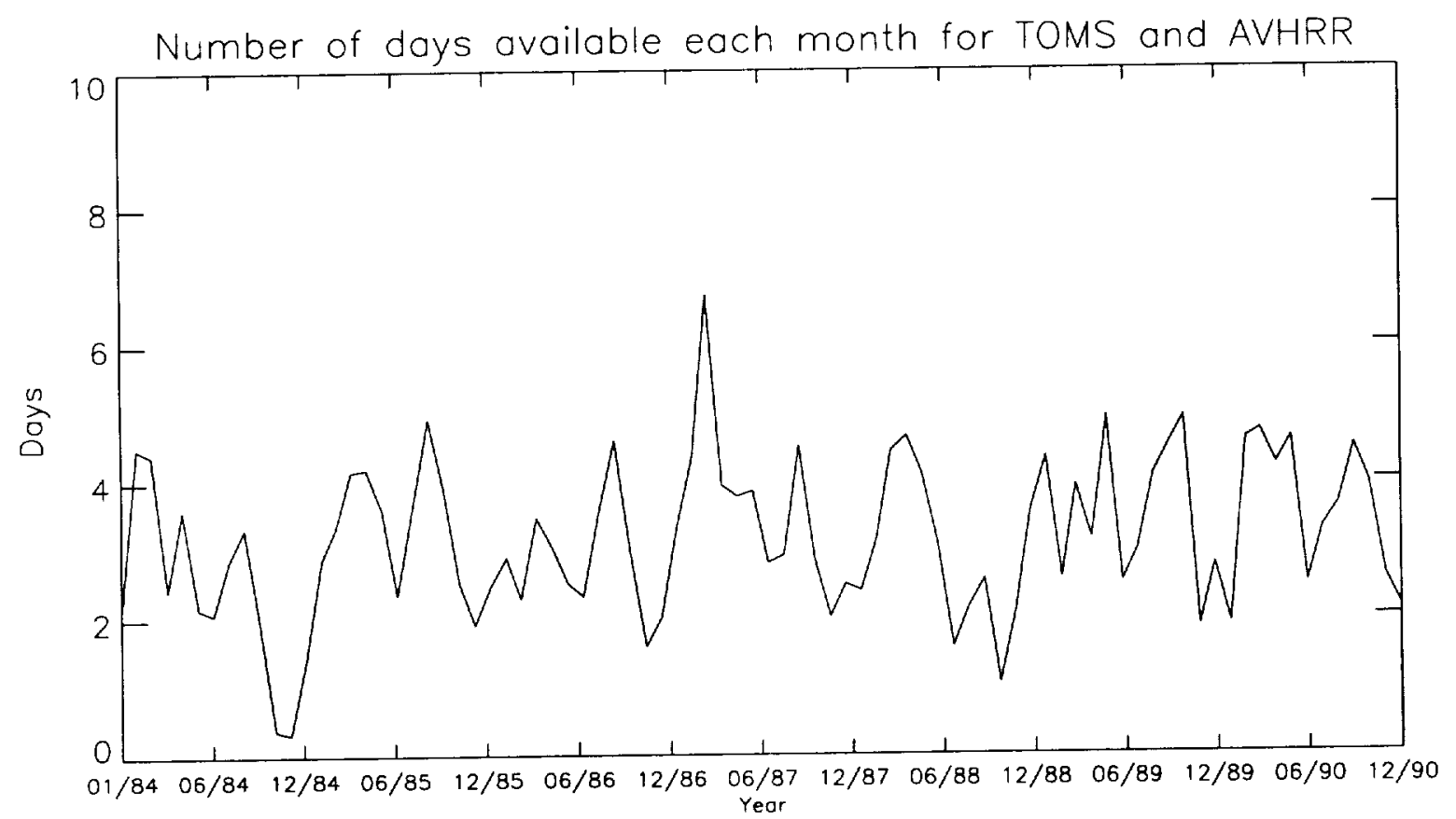

Figure 10. The number of days during any particular month when both retrievals are available at a grid point, averaged over the dust region. 
o) Correlation: 1 Doys of TOMS

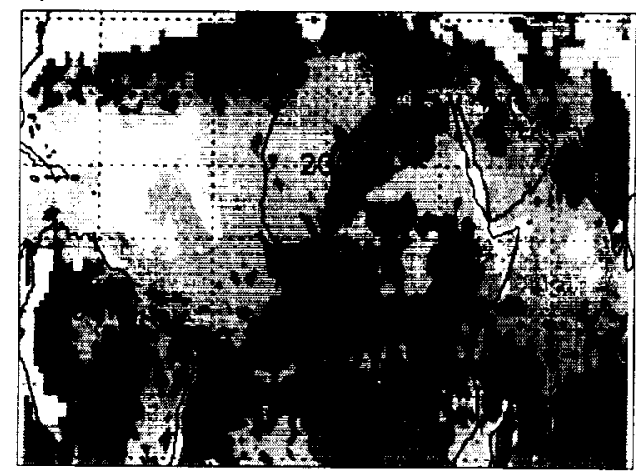

b) Correlation: 3 Doys of TOMS

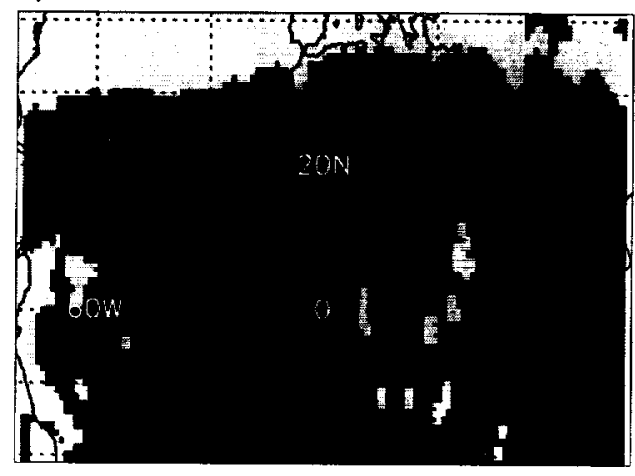

c) Correlation: 5 Doys of TOMS
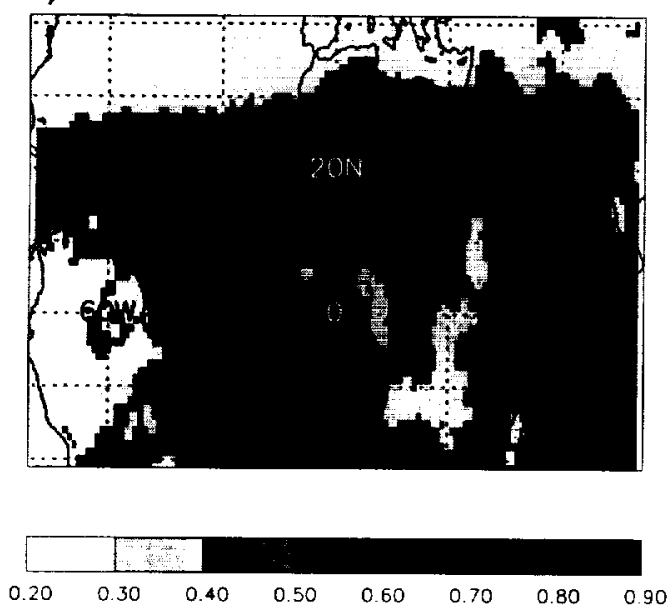

d) Correlation: 7 Days of TOMS

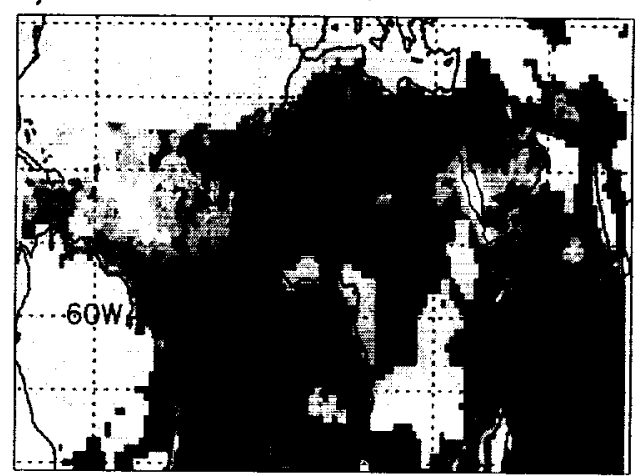

e) Correlation: 10 Days of TOMS

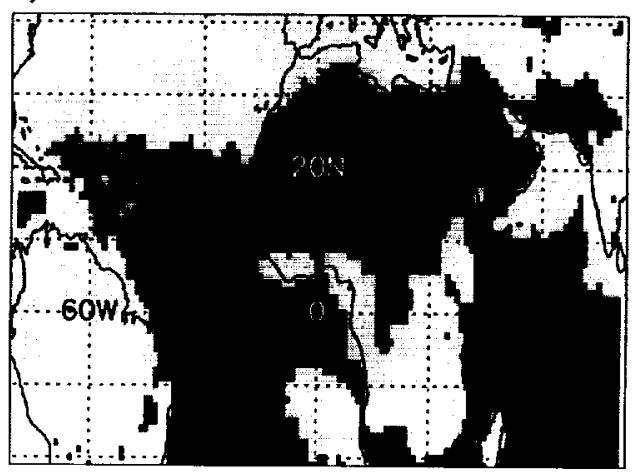

f) Correlation: 15 Days of TOMS
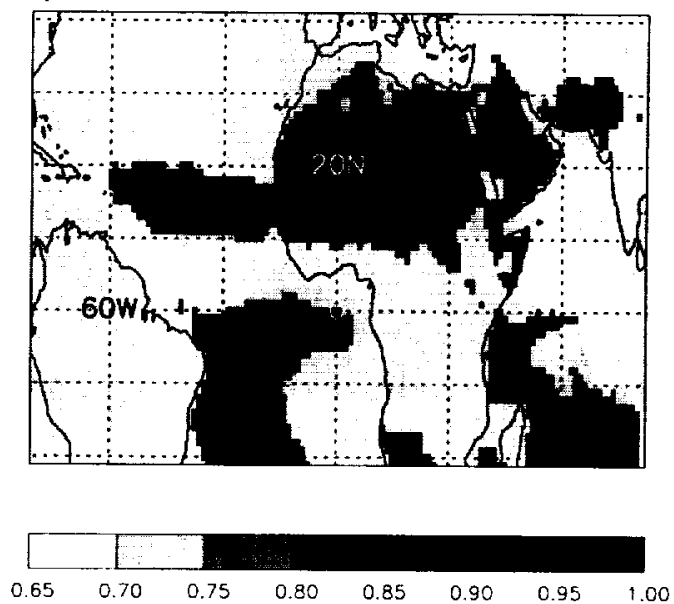

Figure 11. (Color figure) Correlation (after removal of the seasonal cycle) of monthly averages of the TOMS AI with a 'degraded' version of the TOMS AI where monthly averages are formed after discarding daily retrievals at random. Daily retrievals are discarded until the degraded version has a) 1 , b) 3 , c) 5 , d) 7 , e) 10, f) 15 retrievals available to form the monthly average. Correlations are computed at locations where at least 63 months have the minimum number of daily retrievals: e.g. in panel $\mathrm{e}$, this minimum is 10. Otherwise, the location is marked in yellow. 

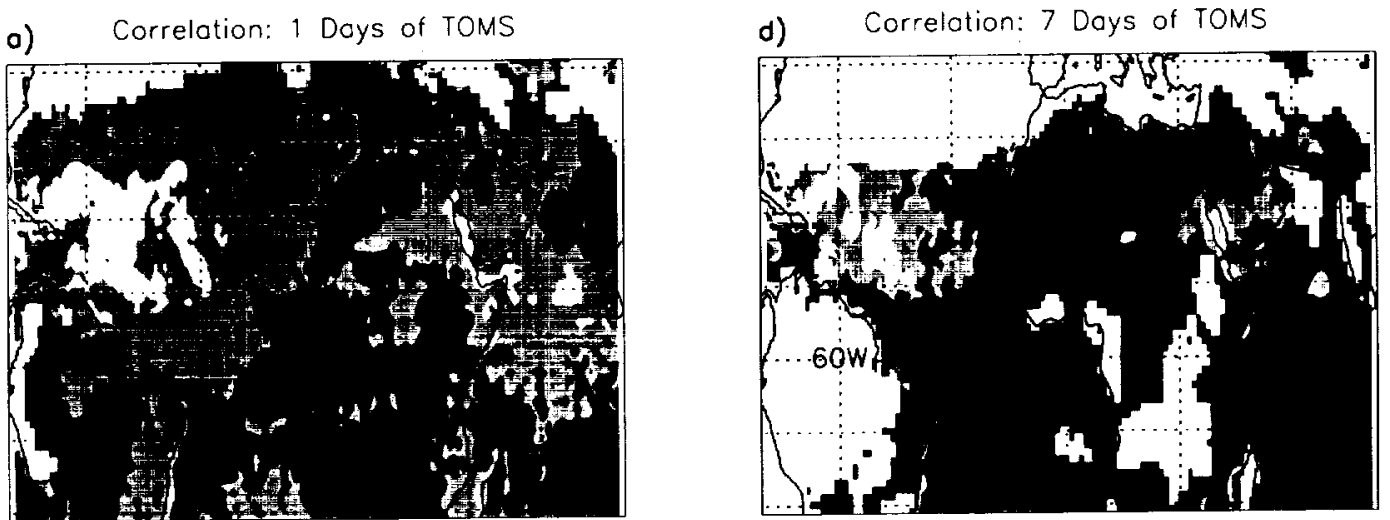

b) Correlation: 3 Days of TOMS
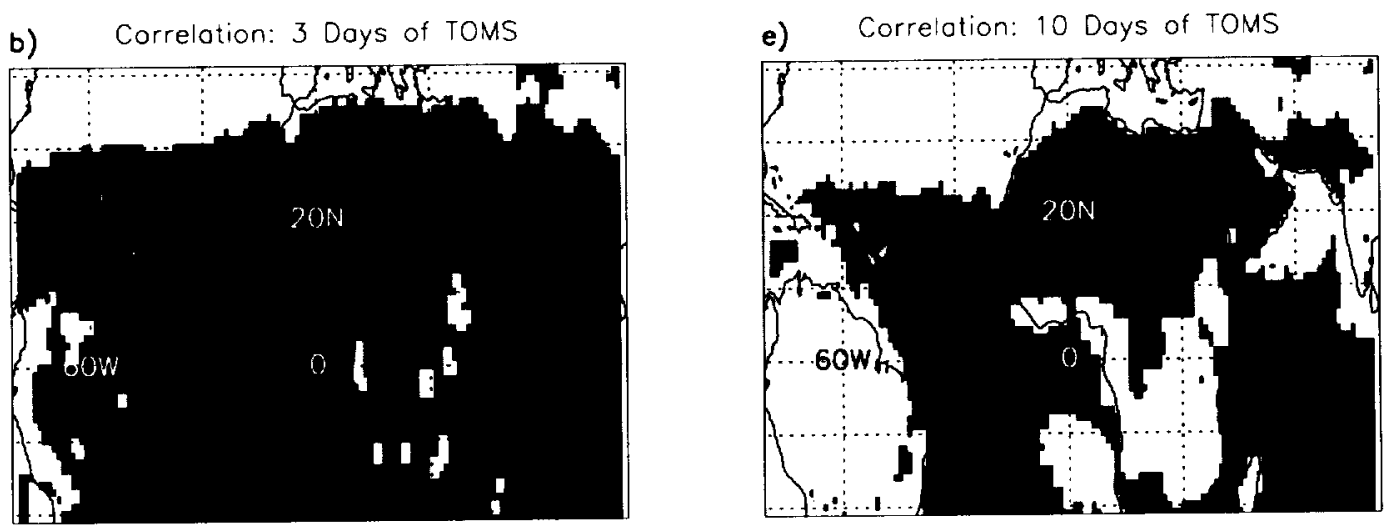

c) Correlation: 5 Days of TOMS
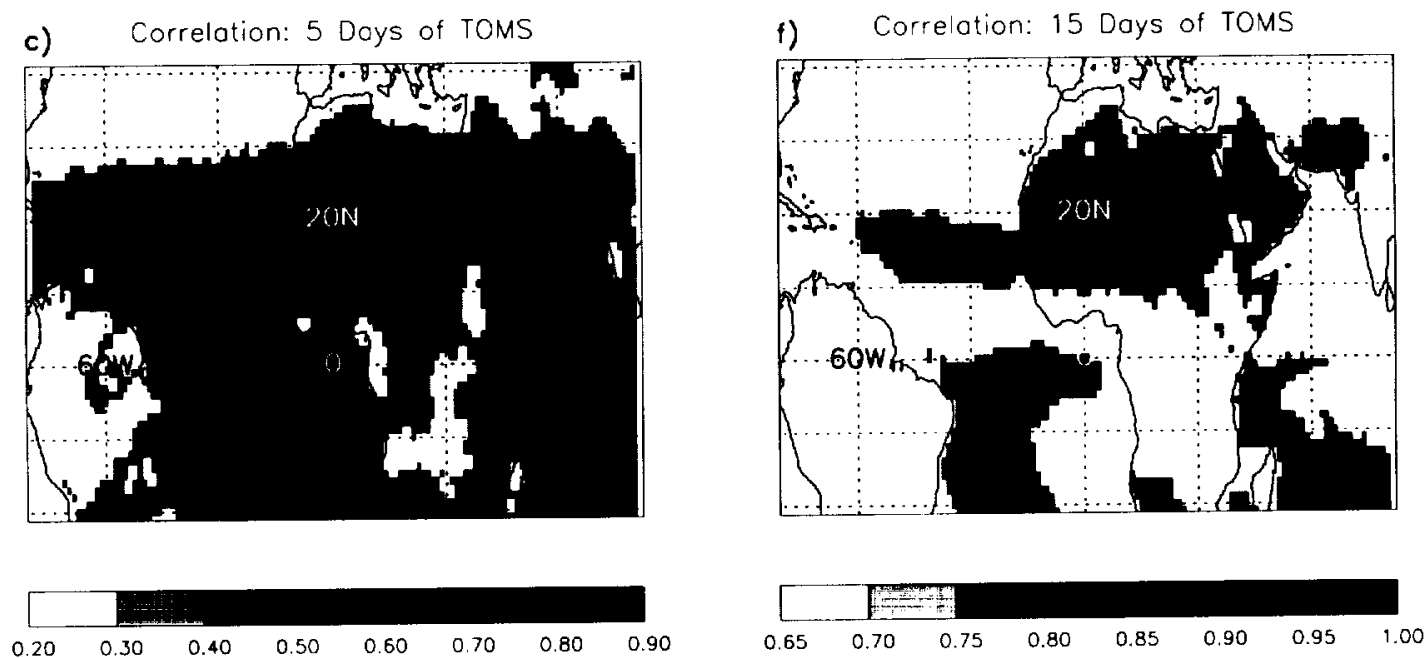

Figure 11. (Color figure) Correlation (after removal of the seasonal cycle) of monthly averages of the TOMS AI with a 'degraded' version of the TOMS AI where monthly averages are formed after discarding daily retrievals at random. Daily retrievals are discarded until the degraded version has a) 1 , b) 3 , c) 5 , d) 7 , e) 10, f) 15 retrievals available to form the monthly average. Correlations are computed at locations where at least 63 months have the minimum number of daily retrievals: e.g. in panel e, this minimum is 10. Otherwise, the location is marked in yellow. 


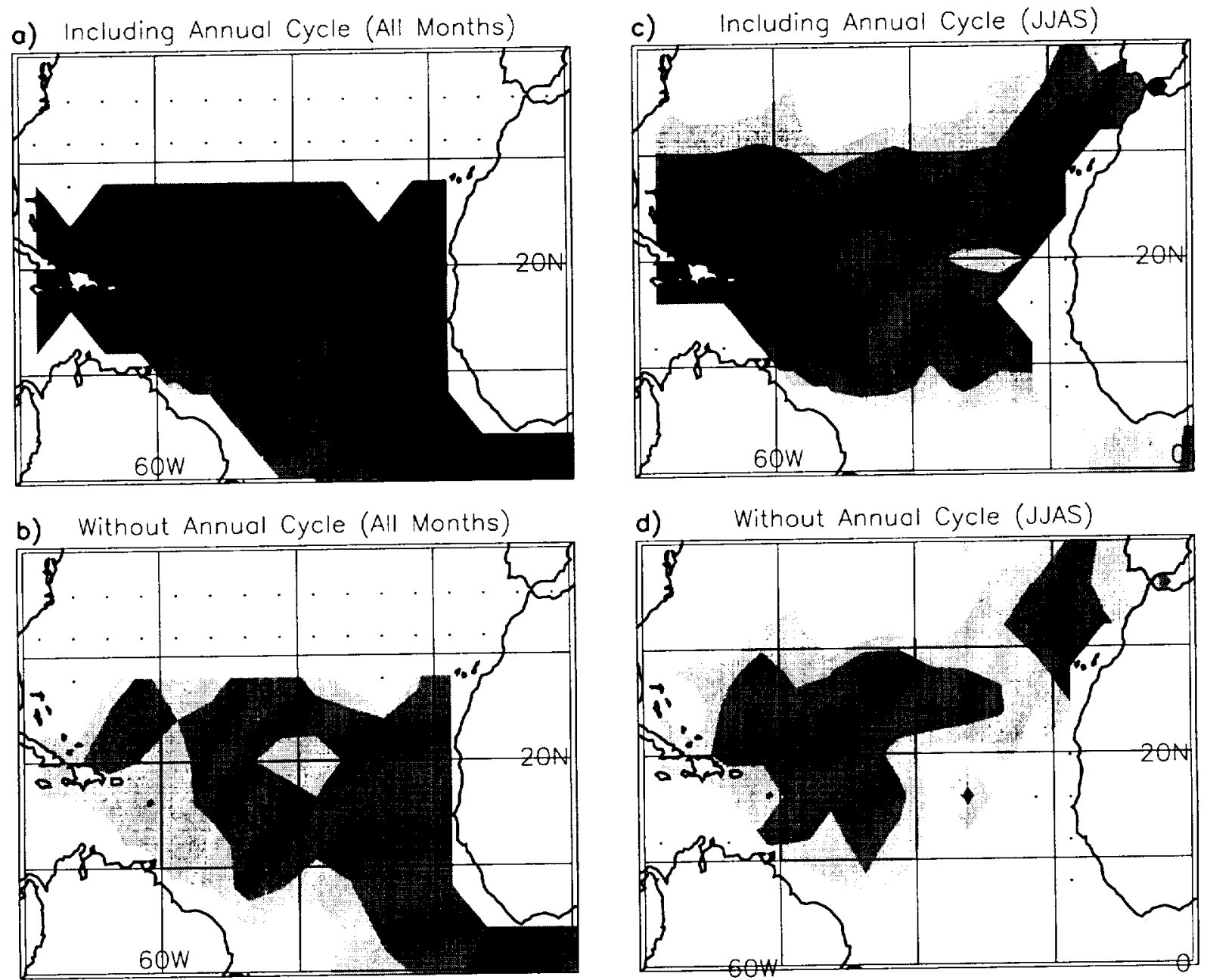

d) Without Annual Cycle (JJAS)
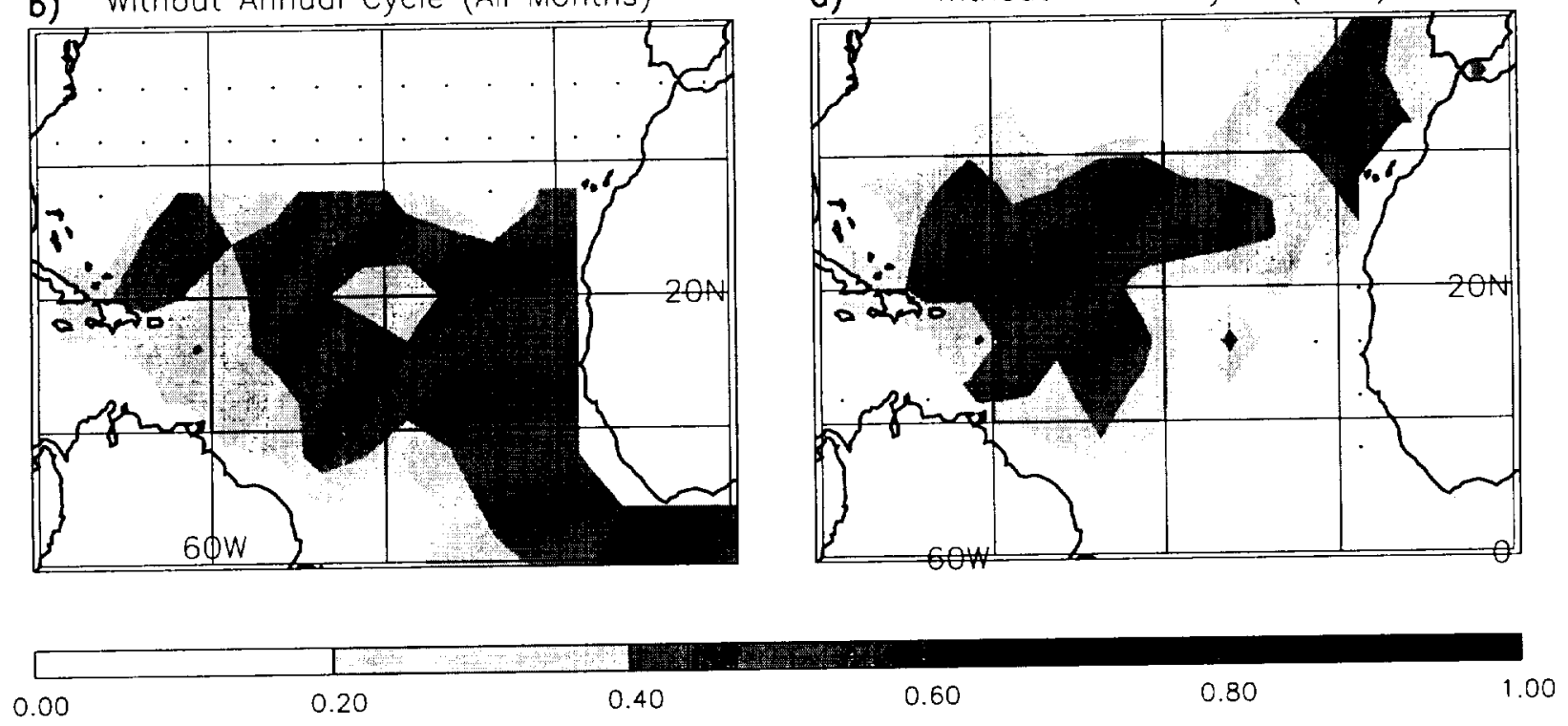

Figure 12. As in Fig. 8, but with both the TOMS and AVHRR AOT rebinned onto a $4^{\circ}$ latitude by $5^{\circ}$ grid. Each monthly average is formed with at least 10 daily retrievals. 
